Portland State University

PDXScholar

1977

\title{
Women in menopause: a study of gynecologist's perceptions
}

Zadell Cogan

Portland State University

Sharon Kennedy

Portland State University

Follow this and additional works at: https://pdxscholar.library.pdx.edu/open_access_etds

Part of the Health Communication Commons, and the Obstetrics and Gynecology Commons Let us know how access to this document benefits you.

\section{Recommended Citation}

Cogan, Zadell and Kennedy, Sharon, "Women in menopause: a study of gynecologist's perceptions" (1977). Dissertations and Theses. Paper 1996.

https://doi.org/10.15760/etd.1995

This Thesis is brought to you for free and open access. It has been accepted for inclusion in Dissertations and Theses by an authorized administrator of PDXScholar. Please contact us if we can make this document more accessible: pdxscholar@pdx.edu. 
WOMEN IN MENOPAUSE: A STUDY OF

GYNECOLOGIST'S PERCEPTIONS

\author{
by \\ ZADELL COGAN \\ and \\ SHARON KENNEDY
}

A practicum submitted in partial fulfillment of the requirements for the degree of

\author{
MASTER \\ OF \\ SOCIAL WORK
}

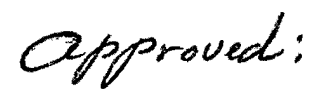

Portland State University

1977 


\section{ACKNOWLEDGMENTS}

Many people have contributed their time and energy to this study. We are very grateful for their participation. We would especially like to thank the following people for their support and advice:

$$
\begin{array}{ll}
\text { Our Advisor, } & \text { Betty Leonard, MSW } \\
\text { Faculty Members, } & \text { Nancy Koroloff, MSW } \\
& \text { Dr. Gerald Frey } \\
& \text { Dr. James M. Whitely }
\end{array}
$$




\section{ABSTRACT}

The purpose of this study was to explore the needs of women experiencing menopause. Since women at this time experience physical, social and emotional changes, they may have a special need for services.

Doctors were selected as the population for study because they treat so many women at this age and because they are powerful transmitters of our culture. This exploratory study was designed to provide descriptive information about the doctors' perceptions.

Results are reported from interviews with seventeen gynecologists from the Portland metropolitan area in Oregon. Attempts were made to interview all female gynecologists in the area. Male gynecologists were randomly sampled and the sample was stratified to ensure representation of doctors from a pre-paid medical plan. Doctors were questioned about definitions of menopause, treatment, and use of community resources.

Overall, it was found that doctors hesitated to make generalizations about patients. This seemed especially true in regard to questions about the effects of menopause or the problems women experience. When speaking about both their definition of menopause and the types of problems associated with it, female physicians tended to limit responses to the 
biological aspects of menopause. Generally, it was the male doctors who stressed the social or emotional aspects.

The major forms of primary treatment used by doctors were: hormone replacement therapy; talking to the patient (i.e. providing education or reassurance about menopause); or some combination of the two depending upon the individual patient's problem. Degree of hormone use varied among doctors. Yet, at some time, with some patients - all doctors used some form of hormone treatment. Generally, Kaiser doctors appeared to use a lower rate of hormone therapy than doctors in private practice.

Most doctors were aware of the existence of community resources. Kaiser doctors tend to most frequently use their own social service department or mental health clinic to handle the other-than-medical problems patients might experience. The community resources which received the highest mention overall were mental health clinics and members of the clergy. The next most frequent category was other mental health professionals.

Six of the seventeen doctors interviewed named services, not now in existence, which they would use if available. Those most frequently mentioned were groups and information \& referral services.

Most doctors believed that the needs of women at the time of menopause were different from the needs of other women. Most frequently mentioned were changes in the women's family structure, changes in her activities, and feelings of 
being no longer needed.

Several doctors who were interviewed echoed researchers such as Bernice Neugarten and Pauline Bart in stressing the negative attitudes which our society has towards women at the age of menopause. In addition, many of the gynecologists expressed awareness of social needs.

The results of the study indicate that doctors' services are primarily involved with treatment of medical or biological concerns, and referrals are generally to mental health resources. Several doctors mentioned social needs of the women; and as has been noted, the need for attitudinal change. Social workers can play important roles to bring about these changes. Two possible approaches are suggested: education to increase awareness of medical and social work professionals and the establishment of new resources to advocate for women at the time of menopause. Suggestions for further research are also given. 
TABLE OF CONTENTS

ACKNOWLEDGMENTS ........................

PAGE

CHAPTER

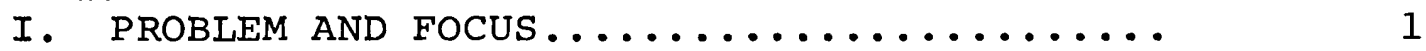

II. DISCUSSION OF ISSUES ................

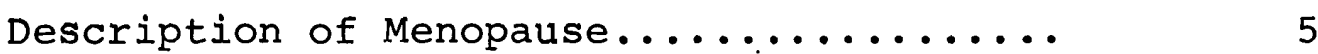

Estrogen Treatment Controversy........... 18

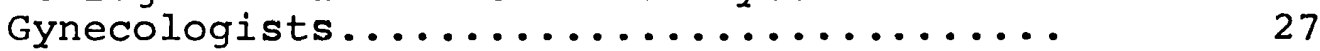

Is There a Male Menopause?.............. 32

III. METHODOLOGY..................... 35

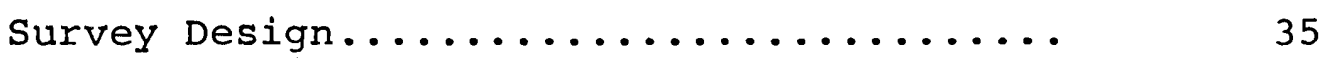

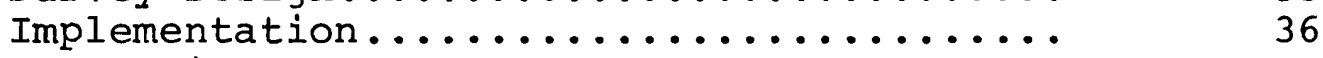

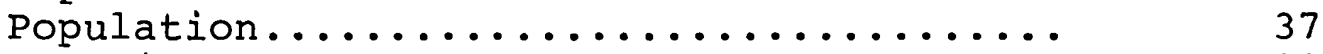

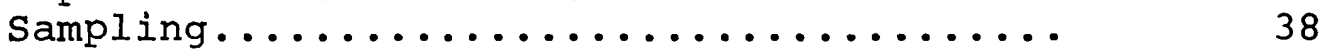

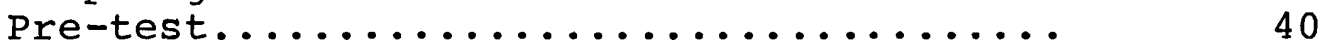

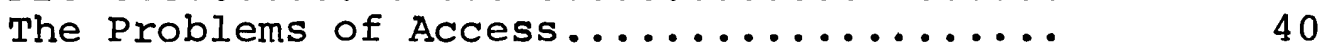

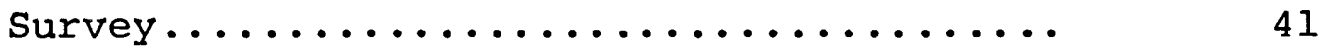

Analysis and Presentation of Data........ 42

IV. PRESENTATION OF THE DATA................ 44

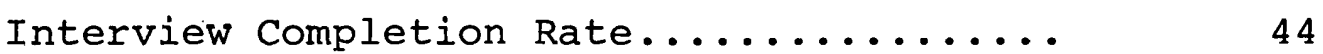

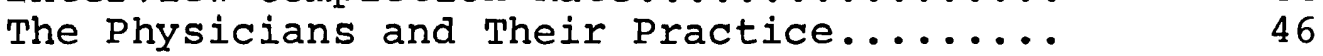

Description of Menopause................. 50

Doctors' Descriptions of the Types

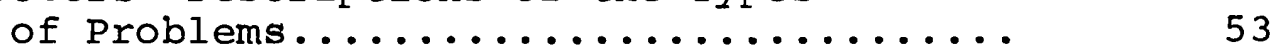

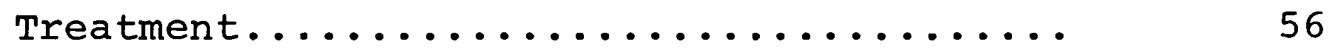

Awareness and Use of Community Resources.. 65

Doctors' Perceptions and Attitudes........ 76

V. DISCUSSION AND CONCLUSIONS ............ 86

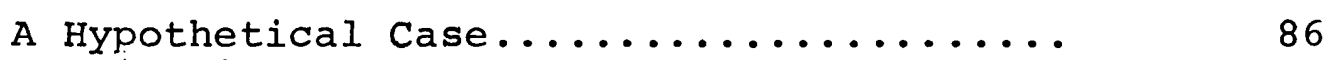

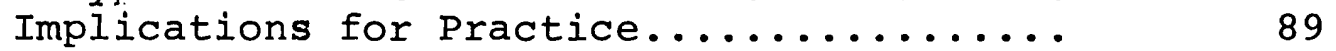

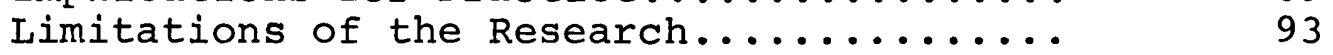

Suggestions for Further Research.......... 94

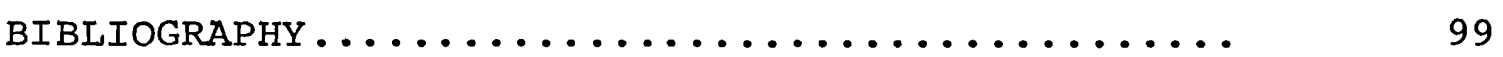


A. Letter to Sampled Doctors and

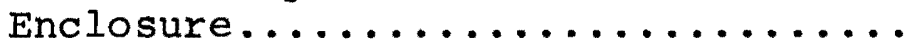
104

B. Interview Schedule...............

C. Letter of Acknowledgment............ 
CHAPTER I

\section{PROBLEM AND FOCUS}

Although social workers are called on to work with problems of women at the age of menopause, there is little in the literature regarding this topic. Recently, there have been many articles regarding social work with women, but very little published specifically about middle-aged women (Klass \& Redfern 1977). A survey of social work abstracts from the past 22 years produced no articles relating to menopausal women and only three dealing specifically with middle-aged women. All three of these articles appeared since 1970; the most recent in February, 1977.

The menopause itself has been a relatively neglected topic for systematic investigation, and the studies that have been made often fail to define the population or use poor sampling techniques. McKinlay and McKinlay (1973) note that "of the research reported, the predominant characteristics are poor planning and design and a general lack of interest in providing comparable or consistent data." "It has been suggested that because, at least in western societies, the menopause has symbolized the end of social usefulness: it has been a stigmatizing event and, therefore, something to be ignored" (Christie-Brown \& Christie-Brown 1976). 
Because the subject has been "inexcusably neglected by the male dominated medical profession," the Boston Women's Health Book Collective (1976) encouraged women to research and study menopause. Dr. Bernice Neugarten (1967), a noted sociologist who has studied women at middle age, bemoans the fact that psychologists have produced no systematic studies of the "belief-systems" that surround the menopause. After many years of studying menstruation and menopause, Paula Weideger (1976) is convinced that much more research needs to be done. She feels that it might be particularly instructive to investigate attitudes of doctors, especially gynecologists, regarding their attitudes toward menstruation and menopause.

Indeed, most studies that have been done about women experiencing menopause have focused on the women. None were found that focused on the doctors who see so many of the women at this time.

There are a number of factors that have stimulated new interest in the topic of menopause. First, people are living longer; more women are living past menopause. A female born in 1900 had a life expectancy of only 50 years, while today she can expect to live until 78 years (Cherry 1976). A woman can expect to spend one thire of her lifetime after the menopause.

Secondly, the availabijity of hormone therapy (Christie-Brown \& Christie-Brown 1976, McKinlay \& McKinlay 1973) for the treatment and prevention of menopausal symptoms 
and the controversy surrounding it has increased interest in the menopause.

The women's liberation movement has encouraged women to take a new interest in their sexuality and their health. The result has been the growth of women's health collectives, forums, and clinics all over the country. Some of these are studying or providing services for women experiencing menopause. The best selling book our Bodies Ourselves (1976) is the product of a health collective in Boston.

In addition, the burgeoning population growth (and possible over-population) world wide has stimulated studies of fertility. The age of onset of menopause becomes part of these studies (Christie-Brown \& Christie-Brown 1976, McKinlay \& McKinlay 1973).

There is precedence for concentration on the needs of a special age group such as middle-aged women. The American public has become increasingly aware of age differences and special needs of individual age groups. Historically, children, adolescents, and the aged have been singled out for attention (Neugarten \& Moore 1968).

The trend is for professions and agencies to specialize by age groups. Teachers specialize in early childhood, primary, intermediate, and secondary education, and physicians specialize in pediatrics and geriatrics. Perhaps nowhere has age specialization been so notable as in the social sciences. Social workers have specialized in child welfare concerns for over a century. More recent specialties have 
emerged serving the needs of adolescents and the aged (Neugarten \& Moore 1968).

Women around the age of menopause have unique experiences and needs and there are few services designed to serve their age group. They are, therefore, an appropriate group for study. 
CHAPTER II

\section{DISCUSSION OF ISSUES}

\section{Description of Menopause}

The term menopause literally means: the final cessation of menstruation or menstrual periods (Webster 1975). The word derives from the Greek meaning "cessation of the month" (Weideger 1976). Menopause is said to have occurred when 12 consecutive months have passed without menstruation. The term menopause is commonly used to describe not only the physical stopping of menstruation, but the period of time leading up to and surrounding this happening. Women who are experiencing changes around this time are spoken of as menopausal.

A more precise term for this period of time is "climacteric" which is derived from the Greek meaning, "rung of the ladder" (Cherry 1976). The dictionary describes it as "a period of crisis" (Webster 1975). This term more accurately describes multiple changes occurring over a period of years with menopause as only one symptom of this period. The term menopause was selected for use in this survey because it is so commonly used and so easily recognized.

Recent literature has suggested that the median age of menopause has increased by approximately four years over the 
past century. Today in the United States, as in most western countries, the median age for menopause is about 50 years (Gray 1976). It is called "premature menopause" when it occurs earlier than age 40; and 958 of women have attained menopause by age 53 (Cherry 1976). It is not possible to predict the exact age that menopause will occur in women. Factors of heredity, race, constitution, and society all help determine the age of menopause. There is some indication that age of onset may vary with residence and geographical origin, as well as nutritional standards. Gray (1976) noted that "the extremely low median ages at menopause [43.6 years] suggest that poor nutrition may be associated with premature menopause...."

Biological Aspects. The ovaries of the woman contain egg cells or ova, one of which is usually discharged midway during the menstruation cycle. The ovaries also produce the sex hormones: estrogen and progesterone. Every girl baby is born with thousands of ova. Of these, about some 400 actually mature. Once the eggs are used up, fertility ends, and the production of the sex hormones begins to decline (Cooper 1975, Weideger 1976).

The function of the sex hormones in the menstrual cycle is to build up the lining of the uterus to prepare for the fertilized egg. If conception does not occur, production of hormones arops for a short time, the lining of the uterus sloughs off and menstruation takes place. With the end of fertility and the decline of the sex hormones, menstruation 
flow ends resulting in menopause. Even if a woman takes sex hormones, fertility cannot return because egg cells cannot be revitalized. In most cases, menstruation decreases gradually, but in some women menstruation ends suddenly.

Since the amount of estrogen affects other tissues in the body besides the uterus, other physical changes may occur in addition to cessation of menstruation. The extent of these changes depends on the pattern of estrogen decrease. The rate at which estrogen diminishes is important. If the amount of estrogen produced in the ovaries drops off suddenly, symptoms of menopause will be severe. The slower the decrease of estrogen, the milder the symptoms will be, or there may be no symptoms at all (Weideger 1976).

"Presumably there are other sources of estrogen supply after the menopause, since this hormone has been found in the bloodstream of women who have had their ovaries removed" (Weideger 1976). No one knows what the source is, but it is suspected by some that the adrenal glands produce estrogen after the ovaries stop functioning. It is also suspected that the adrenals may produce progesterone.

The endocrine system in the body is very complicated and interdependent. In response to the decreased production of estrogen and progesterone, the pituitary gland increases its production of an ovary-stimulating hormone called FSH (follicle stimulating hormone). The large amount of $\mathrm{FSH}$ in the blood may cause an upset in the intricate glandular balance. The body's attempt to achieve new balance (in 
addition to the loss of estrogen) may also cause symptoms (The Boston Women's Health Book Collective 1976).

Some common physical symptoms that take place around the time of menopause are "hot flushes or flashes" and "night sweats." These are generally called vasomotor symptoms and are associated with rapid changes in the diameter of the blood vessels. Women experience sudden and rapid changes in body temperature, causing perspiration and sometimes feelings of suffocation. Redness of the face and body is sometimes observable. Dizziness, nausea, or heart palpitations may also occur (Weideger 1976).

With the onset of menopause, vaginal mucous membrane becomes thinner and dryer which may cause itching. The vagina and the urinary tract become more susceptible to infection. Sexual intercourse may become painful. Ioss of subcutaneous fat causes loss of skin tone and wrinkling. Breasts may become flabby and nipples become flat. Hormonal imbalances may cause facial hair to increase in some women, while the hair on the head may become thinner. Another physical symptom is a peculiar crawling sensation near the body surface. The medical term for this is "formication" (Coopex 1975).

The occurrence of osteoporosis, a condition where the bones become more porous and brittle, and atherosclerosis, the accumulation of fatty deposits in the arteries, rises sharply in women around the age of menopause.

Symptoms vary with individual women and not all women 
experience physical symptoms of menopause. An estimated $10 \%$ of women experience no symptoms at all. Although $80 \%$ will experience one or more symptoms, only $10 \%$ have symptoms severe enough to interfere with their daily routine. About 30 응 of menopausal women seek medical attention for symptoms (Weideger 1976).

Some investigators of the menopause maintain that the only true menopausal symptoms are the stopping of menstrual flow and the hot flush and other vasomotor symptoms. They prescribe to the "endocrine-factor theory" which maintains that symptoms of menopause are due to hormone imbalance (Neugarten 1967). Treatment prescribed for this imbalance is hormone replacement therapy which will be described in more detail later.

Others believe hormones affect emotions and precipitate psychological manifestations which are sometimes associated with menopause.

Psychological Aspects. For many years, a depressive illness called "involutional melancholia" was thought to be associated with menopause. Opinion has now swung away from this view, but the idea has lingered on that severe depressive illness with mood change and periods of self-blame and guilt is associated with menopause (Christie-Brown \& Christie-Brown 1976). In a 1973 study, winokur found that although psychiatric illness seems to increase with age there was no association between depressive illness and menopause. Psychiatric symptoms, rather than illness, are thought 
to be associated with menopause, and psychiatric symptoms are relatively common at all ages. It is often difficult to decide which symptoms can be designated as psychiatric. Anxiety, depression, irritability and emotional lability are usually thought to be psychological in nature. There is some uncertainty about other symptoms thought to be associated with menopause. Headache, insomnia, fatigue and apathy are sometimes listed as psychiatric problems but could be related to organic illness (Christie-Brown \& Christie-Brown 1976).

There has been controversy about whether or not the symptoms form a pattern, the so called "menopausal neurosis" or "menopausal syndrome". Large scale surveys do not suggest any such pattern. Neugarten and Kraines (1965), for example, studied psychological symptoms in women from age 13 to 35 . Tiredness, irritability, and depression were the most common symptoms found in all ages.

Another psychological theory wich may affect the way doctors deal with women at this age is the "emotional-factor theory," which emphasizes the pre-menopausal personality of the patient. The basic premise is that those women who suffer with menopause are so predisposed by earlier life experience or psychosexual trauma (Neugarten 1967).

Stern and Prados (c.f. Huyck 1974) studied women referred for psychiatric investigation of menopausal symptoms and found a long history of maladjustment characterized by economic and social deprivation. After studying a similar group, Dr. John Donovan (1951) concluded that psychiatric 
symptoms could be related to the previous life pattern, and that "in some instances, a patient's entire life has been climacteric." It should be noted that these studies were based on observations of pre-selected groups of women who have been referred by gynecologists to psychiatric clinics (Christie-Brown \& Christie-Brown 1976).

Psychoanalytic writers have also stressed the personality attributes leading to the susceptibility to psychological symptoms of menopause. Their writings are based on a classic theory of psychosexual development, which holds that in order to make a satisfactory adjustment to adult sexuality, a pre-pubertal girl must come to terms with her feelings of envy and inferiority arising from her lack of a penis. They maintain that if this conflict is not reconciled, suppression of the "longing for a different gender may take place" (Christie-Brown \& Christie-Brown 1976). To compensate for this, the adult woman may overvalue the reproductive role. When menopause comes and reproductive capacity ends, old feelings of "bitterness, hopelessness and frustration" are again exposed (Christie-Brown \& Christie-Brown 1976). Psychoanalyst, Helene Deutsch's (1945) ideas have been particularly influential. She considers menopause as a "symbolic castration", and feels that one of the most difficult tasks in a woman's life is the mastery of the psychological reactions to menopause. Therese Benedek (c.f. Neugarten $1976)$ sees fluctuations of menstruation or dysmenorrhea (painful menstruation) as a rebellion against the female 
role. She feels that the energies used coping with feelings surrounding menstruation are released at menopause to be used for psychological growth and social expansion.

A 1970 study by Moaz (c.f. Christie-Brown \& ChristieBrown 1976) of childless Oriental and Arab women in Israel does not support the hypothesis that menopausal problems are a reflection of early psychosexual maladjustment.

In a recent text on menopause, Christie-Brown and Christie-Brown (1976) warn that "there is danger in trying to see a complicated process in black and white terms." They conclude that it may be an "over-simplification" to think that depression and anxiety during menopause are pathological. Menopause, after all, is an unavoidable sign of aging and mortality which most people rebel against. A woman who has had a satisfying reproductive life will naturally feel some sadness at menopause. They feel this may be a normal reaction and "a necessary part of the process of readjustment."

There is also the belief that psychological symptoms may be a result of physical stress during menopause. "Continuous and unrelieved physical distress may result in depression," and lack of sleep caused by "night sweats," could contribute to irritability and nervousness (The Boston Women's Health Book Collective 1976).

There is a wide range of opinion about the effectiveness of estrogen in treating psychiatric symptoms. The literature seems to indicate some improvement of 
psychological symptoms and general feelings of "well being" from the use of estrogen therapy, but there is need for more definitive study (Christie-Brown \& Christie-Erown 1976).

Social Aspects. "Mid-life crisis is not so bad", states a recent news cartoon, "it just comes at an awkward age!" (Oregonian 1977). In our society, menopause does indeed come "at an awkward age" for women. It comes at a time when women are losing societal roles through which they have traditionally defined themselves. Children are growing up and leaving home; parents may become ill or die; and husbands may be directing their energies away from home toward work or perhaps a younger woman. Women often face divorce or widowhood at this age. There is some evidence that the occurrence of menopause itself is not as much a crisis as the social changes happening around the age of menopause. Sociologist, Pauline Bart $(1970,1974,1975)$ points out that when we lose roles throughout life, there are new roles to replace old ones and "rites of passage" to ease the transition. "There is no bar mitzvah for menopause." "Middle age," she says, "is when women's images of their future catch up with reality, and many women are confronted with their nothingness."

Dr. Bart examined records of 533 women between the ages of 40 and 59 who had been hospitalized for the first time and compared them with other women who had functional non-organic diagnoses and conducted 20 intensive interviews. She found that loss of mother role had a direct relationship to depression in middle-aged women. She concludes that this 
depression was not coming primarily from hormonal changes of menopause, but from life cycle changes. When the children, from whom the woman has drawn her identity and based her feelings of self-esteem, depart, there is nothing to replace the loss. This seems to be reinforced by cultural patterns. "I would like to point out," she writes, "that if we define psychosis as being unaware of what reality is, these women were not psychotic. They knew exactly what reality was, that was why they were depressed."

Marion Crawford and Douglas Hooper (1973) studied women in Bristol, England focusing on three potential "crisis events" in the family associated with menopause: the departure of children in marriage, arrival of the first grandchild, and retirement. The median age of the middle and working class women was 49 years. They found that menopause by itself was not a critical transition for women. It became critical only when it is "associated in other ways with other life events." Menopause, for the women studied, was not associated with age identity. They concluded that the menopause experience is handled more easily by most women "than a number of modern myths would suggest."

A study by Bernice Neugarten (1967) seems to confirm some of these findings. When interviewed, large numbers of middle-aged women from varying backgrounds tended to minimize the significance of the menopause in producing anxiety or stress compared to other life events. Only four out of 100 women thought of menopause as a major source of worry. 
More important concerns were: possible widowhood, getting older, fear of cancer, and children leaving home.

The women were eager to talk about menopause and wanted more information and more communication. It seemed that menopause was a taboo topic with husbands, friends, and neighbors. There were no informal social supports around menopausal women as are evident around pregnant women or a new mother.

Paula Weideger (1976) placed much of the blame for stress during menopause to the "negative connotation" our culture has historically placed on both menstruation and menopause. It is not possible to separate the experience of menopause from the social evaluation placed on the occurrence. Unlike the positive evaluation society places on pregnant women, there is no priority placed on the experience of older women. "At best, menopause is considered somewhat ludicrous, and at worst, it is labeled a disqualifying crippler." Women, therefore, try to hide the condition to avoid ridicule or discrimination. Societal evaluation, although not the primary cause of physical changes, does affect the ways women experience those changes.

Weideger feels that the negative way women think of menopause and the emotional and social way they experience the phenomenon grows from the legacy of the menstruation taboo. She contends that the distortion of women's image of herself begins at menarche and derives from "what men think women are." This, she feels, has kept women from sharing 
their experiences.

Part of the problems that women face around the time of menopause may be caused by the way society views middleaged women. Dr. Sheldon Cherry (1976) proposes that society may be a "greater culprit than physiology, especially a society like ours which worships youth and beauty." He and others observe that we live in a youth oriented culture which prizes youthful appearance, sexuality, and reproductive capacity and childbearing roles for women. Mass advertising sells products urging women to keep forever young. Modern societies, says Susan Sontag (1975), "condescend to the values of maturity and heap honors on the joys of youth." Living in this atmosphere, a woman who sees visible signs of aging and her reproductive role decline may well feel threatened. Sontag sees aging for women as a "humiliating process of gradual sexual disqualification."

"Aging is much more a social judgement than a biological eventuality" (Sontag 1975). There is a "social clock" that tells people when they are growing older, and what society expects of them. Stereotypes of aging, growing out of these expectations, may be internalized by women causing them to feel unwanted and useless. They become victims of society. Palmore and Manton (c.f. Huyck 1974) studied the emotional costs of agism, racism and sexism. They found that agism "costs more." Since each of these variables is "costIy," the combination of an aging woman presents obvious disability. 
Some writers believe that not only have older women been discriminated against, but they have been ignored altogether, leaving them with no viable roles to play in society and no status. Dr. Pam Munter (1976) sees middle-aged women as being an "invisible minority." "They are a kind of nonentity, a non-identity in our culture." Depression and low self-esteem at this time are seen as growing not only from physical symptoms, but from the culture's view of menopause as an ending and a "down-hill grade in life."

Relating how it feels to "be alive and obsolete" in our culture, zoe Moss (1970) writes: "Everything she reads, every comic strip, every song, every cartoon, every advertisement, every book and movie tells her a woman over 30 is ugly and disgusting." "It is considered incredible that a woman might have had experiences that are valuable and interesting and that have enriched her as a person. No, men may mature, but women, just obsolesce." 
The Estrogen Treatment Controversy

Estrogen Replacement Therapy (ERT) is the use of the female hormone to compensate for the loss of estrogen being produced by ovaries of women during menopause. The terms Estrogen Replacement Therapy and Hormone Replacement Therapy are used interchangeably in the literature.

ERT is usually administered orally but can be administered by injection or by pellet implantation. There is natural estrogen produced from the urine of pregnant female animals or synthetic estrogen which is chemically produced. Natural estrogen is more costly. There are many pharmaceutical companies producing estrogen under a variety of brand names. The most widely used is "Premarin" (Weideger 1976). The replacement of hormones in menopausal females was discovered in 1923 (Lupton 1976), but the use of this therapy has increased most rapidly in the past ten years.

In 1959, Dr. Minnie Goldberg, a pioneer in the study of menopause, collected and analyzed medical data on treatment into a monograph entitled Medical Management of the Menopause. Dr. Goldberg explained that the autonomic nervous system as well as the psyche, "may be affected by the hormonal balance of the menopause." She cited evidence that lowered estrogen levels affected abnormalties in bone, skin, hair, fluid retention and blood volume, as well as the urinary and gastrointestinal systems. She felt that impaired concentration, insomnia, hot flashes, lethargy, depression, and heart palpitations were symptoms of the menopause that could 
be eliminated "by judicious employment of ERT alone" (Canon 1973).

Doctors at that time, however, were very cautious about the use of estrogen. Doctors, as well as women, viewed menopause as a "natural event" that simply had to be accepted and endured without help.

The menopause received new attention in 1966 when Dr. Robert A. Wilson published his book Feminine Forever. IIe presented the idea that menopause was a "deficiency disease." He compared estrogen deficiency to diabetes. In both cases there is a substance missing in the body chemistry. In diabetes, a lacking substance is supplied in the form of insu1in. "A similar logic can be applied in menopause; the missing hormone can be replaced." He contended that the menopause was not only "curable" but completely preventable." He believed that "no woman need suffer menopause or any of its symptoms if she receives preventive treatment before the onset of menopause," advocating hormone therapy not only before the manifestation of symptoms, but for the rest of one's life. Through the use of ERT, Dr. Wilson envisioned a new tomorrow for women who would be "feminine forever." Dr. Wilson's book aroused new interest in the use of estrogen therapy both by doctors and women. Women began to demand estrogen as a solution to their menopause symptoms and as a bulwark against aging.

Articles written by women between 1966-1976 reflect women's enthusiasm about estrogen replacement therapy and 
the hope that it can bring them relief from menopause distress.

"Once women are alerted to the existence of ERT to eliminate menopause miseries, they set about trying to get it," writes English medical journalist, wendy Cooper. Cooper studied ERT in 1972 after which she presented a television program and published several magazine and newspaper articles containing information available about ERT. With every article and program, she received volumes of mail from women all over the world uncovering a "pool of menopause misery." The women who wrote to her reported that their doctors had resisted using ERT. Cooper believes, as other women writers do, that women should have the right to choose the kind of treatment they should receive. Her book, Don't Change: A Biological Revolution For Women, published in 1976, has a bias toward ERT, but does deal comprehensively with the topic.

Bernice Neugarten (1967) concluded that studies indicated such positive results for women experiencing menopause that what was now needed was "to inform large numbers of women and large numbers of physicians of the benefits of estrogen replacement and to alter long-held contrary attitudes about letting nature take its course."

Medical Controversy Regarding ERT. The controversy in the medical field today does not center on the value of hormone therapy. There seems to be widespread agreement as to its effectiveness. There is disagreement about the timing 
ind duration of treatment, when and how it should be administered, and the possible risk of cancer (Weideger 1976).

In the June 28, 1974 issue of Medical World News

("Treating Menopausal Women" 1974), two leading gynecologist: presented opposing points of view at that time. Dr. Edmund R. Novak, Associate Professor of Gynecology at Johns Hopkins School of Medicine represents the more "conservative" use of estrogen therapy. Dr. Robert B. Greenblatt, Professor of Endocrinology at the Medical College of Georgia is a spokesman for the more "liberal" approach to treatment.

In this article, Dr. Novak advocates ERT only for the 20 to 258 of patients he estimates to have severe vasomotor symptoms. He defines a "severe" symptom as when a woman has night sweats so severe that she is awakened several times nightly with soaked sheets. "Most patients," he feels, "get along perfectly well if you reassure them that it isn't anything serious, it's transitory." Besides severe vasomotor symptoms, a patient must have stopped menstruating to warrant ERT. When he does prescribe estrogen, it is minimal dosages given orally. He emphasizes to his patients that they can take hormones when they feel they are necessary but that it is desirable to get along without them. Because he does not approve of long-term therapy, most of his patients have hormone therapy for less than a year. He believes that in most cases, symptoms will subside in about a year even without ERT, because the adrenal glands will produce estrogen after the ovaries stop producing the hormone. 
By contrast, Dr. Greenblatt, in the 1974 ("Treating Menopausal Women" 1974) article, looks on estrogen therapy as preventative medicine. He believes every estrogen deficient woman should have ERT before symptoms develop. "Can homespun psychology, assurances, and tranquilizers be expected to arrest the deteriorating metabolic milieu?" he asks. Dr. Greenblatt believes that within a few years of the onset of menopause $75 \%$ of women have an acute estrogen deficit that will last for the remainder of their life. To compensate for this, he often recommends large dosages of estrogen administered either orally, by injection, or pellet implantation. Many of his patients receive therapy for more than 20 years as he believes that a hormone deficit cannot correct itself, and therapy may be needed until the "last day of life."

Most gynecologists' views fall within the views of Drs. Novak and Greenblatt, but there are doctors with an even wider range of attitudes. More radical doctors such as Robert Wilson prescribe large dosages of estrogen with progesterone producing monthly bleeding similar to menstruation. At the same time, there are still some doctors who cling to the idea that no one should interfere with the natural process of menopause, and who never prescribe hormones (Lake 1965).

Estrogen and Cancer Risk. Possible causal association of estrogen with cancer of the endometrium (lining of the uterus) and breast have been suspected for many years. These 
suspicions were based upon studies of estrogen injected into animals in a laboratory. For example, as early as 1932, Dr. A. Lacassagne injected massive doses of estrogen into cancer susceptible mice and produced tumors in an experiment using "stilbestrol" (a coal derivative possessing qualities of estrogen). No studies at this time had produced convincing evidence to validate speculations of cancer risk with estrogen in humans. In addition, practitioners using estrogen therapy found little incidence of cancer in their patients over periods of time (Canon 1973).

Doctors such as Wilson and Greenblatt reported less incidence of cancer among their patients using ERT over long periods of time, and studies using estrogen in monkeys over long periods failed to produce uterine or breast cancer.

There was added knowledge that, although the use of estrogen therapy had increased dramatically during the past ten to 15 years, National Cancer Surveys suggested that the incidence of uterine cancer had not increased in the United States between 1947-1971. The same held true in England, Wales, and Canada (Proudfit 1976).

The first well developed studies on humans linking estrogen use and cancer were published on December 4, 1975. The New England Journal of Medicine reported two independent studies which compared, retrospectively, the use of estrogen in patients with and without endometrial cancer and concluded that the use of conjugated estrogen plays a role in the incidence of cancer. 
Dr. Donald C. Smith and others from the University of washington compared postmenopausal patients with diagnosed carcinoma of the endometrium with a control group with other gynecologic problems. Their study found the risk of acquiring endometrial cancer was 4.5 times higher among women receiving estrogen therapy.

Harry K. Ziel, M.D., and William D. Finkle, Phd. (1975) of Kaiser Permanente Medical Center and the Department of Medical Economics of the Kaiser Health plan of Southern California Region in Los Angeles, compared endometrial cancer patients with controls within the same Kaiser Health Plan and matched them on the basis of age, residence, and length of time on the medication. They found an estimated risk of acquiring endometrial cancer was 7.6 times higher for women treated with estrogen.

Dr. Noel S. Weiss (1975), from the University of Washington, expressed the need for caution and further study. He raised questions, not yet answered, regarding the effect of duration and quantity of estrogen and feels that it may be a few years before we have more definite answers.

The findings of a third study published six months after the first two seem to confirm the results of the previous studies. Dr. Thomas M. Mack and others (1976) from schools of medicine of the University of Southern California and the University of California showed an estimated risk of endometrial cancer to be 5.6 times higher in menopausal women treated with estrogen. The risk was higher where higher 
doses were used and lower if patients had discontinued estrogen therapy for two years or more.

Dr. Robert Greenblatt (1976) cites evidence that the incidence of endometrial cancer itself may be over-diagnosed because the cancer varies so and there tends to be a bias toward diagnosing malignancy. He fears that recent studies pointing out possible cancer risk might cause doctors not to use ERT when women really need it. This, to him, would be a form of "benign neglect."

Doctors seem to be taking a cautious attitude regarding the recent research. In a recent issue of the "Journal of the American Medical Association," Dr. Carol M. Proudfit (1976) acknowledges that the evidence does suggest a "causal relationship between menopausal estrogen therapy and endometrial carcinoma," but believes that "complete elucidation of the risk-to-benefit features of estrogen therapy awaits results of additional controlled clinical studies." In the meantime, the use of estrogens for menopausal symptoms is suggested when the patients are "adequately monitored and are informed of the possible adverse side effects."

It is generally accepted that estrogen should not be prescribed for women who have a history of cancer.

The estrogen controversy provoked Food and Drug Administration Commissioner, Alexander M. Schmidt, to issue a statement regarding the use of estrogen during and after the menopause. This statement was printed in the sunday news supplement, "Parade," on September 19, 1976, and was widely 
read. "It is the FDA's present view, backed by the best science and the best judgement we can bring to bear, that estrogen-containing medicines are useful, effective, and safe, when properly used." Doctors are cautioned against prescribing estrogen routinely, however, and are advised to use the lowest effective dose for the shortest possible time.

The article announced that a brochure listing the purpose, benefits and risks of estrogen was being developed "to accompany each prescription to help women participate in making the best decision." 
Gynecologists

Few women have entered the specialty of obstetrics and gynecology. Only 6.68 of obstetrician/gynecologists are female (Scully \& Bart 1973). This is a smaller proportion than in the medical profession as a whole where women represent $13 \%$ of the profession (Cantwell 1976). Although 1008 of the gynecologist's patients are women, $93.4 \%$ of the gynecologists are men.

There are about 240 practicing gynecologists in Oregon. More than half of them practice in Multnomah County. By the time gynecologists have completed their training, $98.2 \%$ are at least 30 years old (Comprehensive Health Planning Association 1975).

According to a private practice gynecologist interviewed before the survey, gynecologists have varied interests within their specialty. These interests tend to form subspecialties such as endocrinology, oncology, and family practice. Some gynecologists stress the technical or surgical part of gynecology and some, the "art of medicine."

Nationally known Portland writer, Belle Canon (1973)

feels that medical schools do not pay enough attention to the menopause. How much training have gynecologists received regarding menopause? Before practicing, a gynecologist must have completed four years of medical school plus four years of obstetric-gynecology residency. Dr. Leon Speroff, Professor and Chairman of the Department of obstetrics and Gynecology at the University of Oregon Medical School says the 
training medical students receive there about menopause is similar to that of other schools. Medical students hear one lecture on menopause during their second year plus an hour "patient presentation" on the topic. Students have clinical experience in outpatient clinics that cover many disciplines. Their experiences in these clinics is on a two week basis, where they see some middle-aged women patients, although not necessarily regarding menopause. No texts are used although there are several new publications out on the menopause. Texts on the physiology of reproduction usually contain a short chapter on menopause. ${ }^{1}$ Belle Canon (1973) found that the combined number of pages devoted to the menopause in four gynecology textbooks was 26 pages.

A discussion with five gynecology residents at the Good Samaritan Ob/Gyn Outpatient Clinic revealed that their exposure to menopausal problems in clinics is minimal. They agreed that, as residents, they are responsible for examining and treating too large a number of women to have time to discuss menopause related problems with them. Medical students have more time, but the two week rotation system does not allow them to see the same patient twice. One resident suggested that most gynecologists learned about menopause

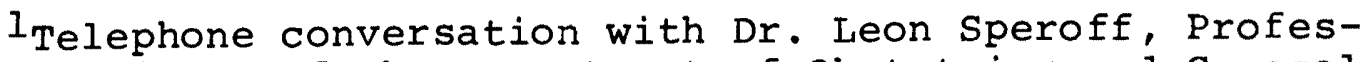
sor and Chairman of the Department of obstetrics and Gynecology, University of Oregon Medical School, March, 1977. 
from their patients after they are in practice. ${ }^{1} \mathrm{~A}$ Portland doctor claims that the nature of clinic experience is "geared to give medical students and residents surgery experience and screens out normal non-surgical or routine things."

Gynecology texts published in the United States from 1943-1972 were examined by Sociologists Diana Scully and Pauline Bart (1973). They found that the texts were written from a "male viewpoint" and were "committed to maintaining traditional sex-role stereotypes." A quote from a 1968 test stated: "If like all human beings, he (the gynecologist) is made in the image of the Almighty, and if he is kind, then his kindness and concern for his patient may provide her with a glimpse of God's image" (Scully and Bart 1973).

Recent writings by women express criticism of gynecologists. More and more, they are challenging their authority. These writers implore women to take a more active role in decisions involving their own health care. Judy Klemesrud (1973) claims that, "The love affair between women and their gynecologists," expressed in adoring worship mixed with blind trust, "is on the rocks."

Paula Weideger (1976) feels that gynecologists enforce a social code common in our culture, that, "a menopausal woman is a pathetic or unsexed creature," who has outlived her usefulness. Gynecologists, she feels, have an inflated

${ }^{1}$ Discussion with residents, Good Samaritan Hospital, February, 1977. 
self-image and authoritarian ways and see themselves as "more royal than the king." She contends that doctors are often prone to look for psychological symptoms, while women are trying to tell them that their "problems are not in their heads but in their bodies."

Betty Friedan and Gloria Steinem, writers identified with the Women's Liberation Movement, express the view that doctors have treated women as children rather than adult patients. Friedan finds the fault in the passivity of women. She anticipates a basic revolution in the practice of medicine, "as women discover their own identity and refuse to be treated as things and objects" (Klemesrud 1973).

Another manifestation of the growing dissatisfaction with the treatment of women by doctors is the development of women's health groups and self-help clinics. The best selling book, Our Bodies, Ourselves, A Book By And For Women developed from a Boston women's discussion group. Some new women's clinics offer courses on topics such as "Methods of Evaluating Gynecological Care" (The Boston Women's Health Book Collective 1976).

The writings by women and inquiries by women's groups imply that the attitudes of gynecologists toward women affect the treatment their patients receive, and that these attitudes come out of a male dominated profession. Published studies of health care professionals, except for nurses, have excluded women. The argument is that such a small percentage of the profession is female that they could make no significant 
difference. This brings up the question whether the attitude and characteristics (example, sex \& age) of the gynecologist have an effect on the treatment patients receive.

Some writers feel that gynecologists are becoming more responsive to women's complaints about their treatment. Judy Klemesrud (1973) interviewed 25 gynecologists across the country and found most of them indicated sympathy for women's grievances and a desire to change their attitudes and practices when complaints seem legitimate. Dr. Philip M. Sarrel, Assistant Professor of Obstetrics/Gynecology at Yale University College of Medicine, says that men entering the specialty today are a "new breed." While ten years ago students entered the field "to make a lot of money and manipulate women," today's students are top people coming into the field because it is "alive and exciting" (Klemesrud 1973). 
Is There A Male Menopause?

Recently there has been a great deal of discussion about the possibility of a male menopause. Since the menopause means cessation of menses, by this definition there can be no male menopause as in the female. However, scientists today do believe that there is indeed a male climacteric, even a male climacteric syndrome, resembling the female climacteric. Male climacteric syndrome is defined as "a cluster of physiologic, constitutional and psychological symptoms occurring in some men aged approximately 45 to 60 associated with hormonal changes" (Klemesrud in "Treating Menopausal Women" 1974).

Dr. Herbert Kupperman, Endocrinologist at New York University Medical Center, defines male climacteric as a time "when gonadal function diminishes, eventually resulting in complete cessation" (Kupperman in "Treating Menopausal Women" 1974). The male hormone, testosterone, slowly diminishes causing a variety of symptoms. The male climacteric is thought to begin a little later than in the female and to be much more gradual.

Some of its symptoms include: morning fatigue, nervousness, depression and diminished sexual potency including the inability to achieve erection. Circulatory signs such as hot flashes, headaches, heart palpitations and dizzy spells are noticed. These symptoms sometimes produce anxiety about heart attack. Perhaps the most bothersome of all is a category that Dr. Thomas Jackobovits calls the "decline 
in psychologic stability" (Sheehy 1976).

Treatment used to reduce these symptoms is hormone replacement therapy, to replace the diminishing male hormone. About $15 \%$ of all males are considered to be candidates for hormone therapy. This treatment is controversial because of the possible danger of stimulating cancer in the prostate gland, a condition that is thought to be latent in onefourth of all men (Sheehy 1976).

Male climacteric is also defined by its psychological aspects, based on a man's ability to adapt to physiologic changes. Dr. Kupperman ("Treating Menopausal Women" 1974) feels that, "If a man has been inadequate from the start, he may be more likely to get severe climacteric depression than well-adjusted men." For men whose sexual prowess is associated with self-esteem, the climacteric may be particularly threatening. For women, menopause is a specific event, but for men the climacteric may be undefined and unexpected, and therefore, be more confusing. Dr. Louis E. Bisch, as early as 1946, observed clamacteric men who look for younger sex partners. He feels that they may be hoping for new stimulation of sexual performance. Although not condoning this behavior, he suggests "tolerance and understanding" as well as possible hormone therapy and psychotherapy.

Writers such as Alex Comfort (1976) deny the existence of physiological male climacteric. He writes that the "male menopause is a gimmicky title for a second identity crisis in males. It has no basis in biology". Many other doctors 
have not been convinced either. Dr. Kupperman ("Treating Menopausal Women" 1974) believes that the skepticism is based on failure to follow through with modern diagnostic procedures. Techniques for testing male hormone levels have been inadequate until recently. 
CHAPTER III

METHODOLOGY

\section{Survey Design}

A specific direction for study was developed through a review of the existing literature and interviews with members of the community. These included talks with a gynecologist in private practice, a sociologist who teaches and writes about women's issues, a social worker who counsels menojausal women at a Kaiser clinic, and the executive director of the Multnorah County Medical Association. This initial research produced a series of statements of need.

A. Women between the ages of 40 and 60 years experience changes: physical, social and emotional. Because of these changes, women in this age group may have a special need for supportive services.

B. The existing literature provides little information regarding their specific needs, including the nature of these needs, whether they are being met in the community, and in what form.

C. Women in this age group frequently are in contact with members of the medical profession. These individuals, therefore, have a rich source of information regarding problems and needs of these women. Because doctors are powerful 
transmitters of the culture, they are in a position to influence women's attitudes towards themselves, as well as the culture's view of the women. There is a need to investigate the attitudes and perceptions of these doctors seeing women experiencing menopause. This study was designed to survey these doctors.

\section{Implementation}

An important methodological concern involved decisions over whether the survey would be conducted by mailed questionnaire or interview schedule, and what type of data would be gathered. A search of the literature found no previous research on menopause focusing on doctors. It was, therefore, decided that the instrument would be designed to provide general descriptive and exploratory information. In addition, it was decided that an interview format would best provide this type of information. Open-ended questions would be used to allow doctors a broad range of responses. The technique of probing would ensure that the answers given would be responsive to the intent of the questions. It was also thought likely that a personal contact with doctors would ensure a greater completion rate than a mailed questionnaire.

An interview schedule was developed that explored the research questions as follows: (See Appendix for Interview Schedule).

1. How do doctors define menopause? see question Number 5 . 
2. What do doctors perceive as the predominant problem associated with menopause? See Question Number 11.

3. What types of treatment are commonly prescribed for women experiencing menopause? See Numbers 6 through 8 .

4. How aware are doctors of the existence of other than medical resources in the community available for women in menopause, and to what degree of frequency do they refer. to those resources? See Numbers 12 through 15 and 17 .

5. How concerned do doctors say they are with the establishment of new resources for these women? See vumber 16 .

6. What kinds of perceptions and attitudes do doctors have toward these women, and their needs? see Numbers 9, 10, 18 , and 19 .

7. Does the sex, age, or type of practice of the doctor affect their perception and treatment of these women's needs? See Numbers 1 through 4.

\section{Population}

The population selected for study was the group of gynecologists practicing in the Portland metropolitan area in Oregon. They were selected because the proportion of women in their practice is greater than other doctors. In addition, their specialty practice made them more identifiable as a group and allowed for a larger proportion of the group to be sampled. Gynecologists were defined as doctors who listed themselves as gynecologists or obstetrician/gynecologists in the Portland telephone directory or at their place of practice. This included gynecologists in private practice, as 
well as doctors who practice at Kaiser and the University of Oregon Health Sciences Center.

A call to the University of Oregon Eealth Sciences Center revealed that gynecologists there spend much of their time in teaching and research, which limits the time they are able to spend with patients. Since the number of patient: these doctors see is relatively small, it was believed that the number of women treated for menopause would be even more limited. On that basis, this group was excluded from the sample.

A list of gynecologists practicing as part of the Kaiser Plan was obtained from the office of the Kaiser-Permanente Medical Care Program to provide a sampling frame for Kaiser gynecologists.

The possibility of using lists of gynecologists from the Multnomah County Medical Association or the state Board of Medical Examiners was investigated. The Board of Mediral Examiners could not provide a current list divided by specialty. The list provided by the Multnomah County Medical Association, when compared with the 1976 Portland telephone directory, was found to be less complete. In addition, it noted that retired doctors were included on its membership rolls. The 1976 Portland telephone directory provided the most complete list of private practice gynecologists currently practicing in the Portland area.

\section{Sampling}

The total number of doctors listing themselves as 
gynecologists or obstetrician/gynecologists in the 1976 Portland, Oregon telephone directory and the Kaiser list of ob/Gyns came to 93 . The decision was made to interview roughly $20 \%$ of this population. This number was determined to be appropriate, based on the amount of time and resources available; keeping in mind that gynecologists are busy people and that gaining access might take a considerable amount of time. ${ }^{1}$

Since sex and type of practice of gynecologists were areas chosen for study, it was desirable to ensure adequate representation from the two small sub-groups: the Kaiser doctors and the female doctors. The sex of the doctor was believed to be of particular importance since the patients seen are $100 \%$ female and the doctors are more than $96 \%$ male. The decision was made to attempt to interview all seven of the female gynecologists (or obstetrician/gynecologists) listed in the Portland area.

Male doctors were further stratified by type of practice. A $20 \%$ sample was selected from a list of doctors in private practice and from a list of male doctors at Kaiser. Each male doctor's name was numbered and each sample was drawn using a Table of Random Numbers.

One of the male doctors listed in private practice was

${ }^{1}$ Discussion with Nancy Koroloff, Research Advisor and Faculty Member, Portland State School of Social Work, July, 1976. 
deceased at the time of the survey and was replaced by another male doctor in private practice, whose name was drawn st random. In addition, one of the female doctors who was interviewed was excluded from the sample results because she stated that she was primarily a surgeon.

\section{Pre-Test}

Two doctors who were not included in the random sample were selected for a pre-test of the interview scheale. One was from Kaiser and one from private practice. The amount of time for completion of the interview averaged 20 minutes. Generally, no major difficulties were encountered. After discussion and suggestions from the doctors, slight modifications were made in terminology and one question was added regarding differing needs of this age group.

\section{The Problems of Access}

Access was considered to be an important issue in this survey. Obstetrician/gynecologists are busy professionals who schedule their day with multitudes of patients' appointments for office visits and surgery. Their busy schedule is further compounded by unscheduled emergency calls for deliveries and emergency surgeries. It was recognized that for these busy professionals to give their time, the survey must be brief, about a topic of interest to them, and be scheduled at their convenience. In order to ensure these criteria were met, a letter was sent to the doctors (See Appendix) describing the purpose of the study and offering respondents an 
abstract of the results of the survey. The letter stated that the interview could be completed in 20 minutes and that the interviews could be arranged at the convenience of the doctors.

The draft of the letter was reviewed by Mr. Robert Elsner, Executive Director of the Multnomah County Medical Society, who suggested enclosing a self-addressed post-card allowing the doctors to indicate the preferred time for appointment calls (See Appendix). Twelve doctors (over 50\%) returned these postcards.

Calls for appointments with responding doctors were begun immediately. Two weeks were allowed to elapse before calling non-responding doctors for appointments. Usually, a minimum of two or three phone calls were necessary to schedule one appointment. Once the doctors were reached, the degree of participation exceeded the expectation of the researchers.

The greatest difficulty was in actual completion of the interview. At times, doctors were unexpectedly called out of the office before being interviewed, and appointments were frequently rescheduled. It was not uncommon to make two trips or more to a doctor's office. Often interviewers spent more than an hour before being shown into a doctor's office or before discovering that the doctor could not (after all) see them that day.

\section{Survey}

The surveyed doctors were very receptive to being 
interviewed and at times went to great lengths to accomodate the researchers. The number of gynecologists interviewed and included in the results came to 17 or 73.98 of the original sample. Most of the interviews were conducted in the doctors' offices. Some were scheduled between patients; some were held after patient appointments were completed; and some were conducted during the doctor's lunch hour. One doctor even sent out for lunch, which he finished while being interviewed. In addition, one doctor suggested that he come to the office of the interviewer and one doctor invited the interviewer to his home.

Generally, doctors were generous with their time. The shortest interview was 20 minutes in length, but most werc longer. One doctor extended the time to two hours.

Most doctors interviewed were very gracious. Although cautious at first, many appeared to genuinely enjoy being interviewed. Several expressed interest in the outcome of the study. In addition to granting an interview, several doctors generously offered other resources. One doctor loaned the interviewer a recent text book on menopause; three noctors gave the interviewer a booklet designed for women going through menopause; and one loaned a tape of a panel discussion of menopause.

The interviews with the gynecologists were conducted during October and November of 1976.

Analysis and Presentation of Data

Due to the exploratory nature of the study, data was 
of a descriptive nature. Data analysis involved the development of categories with hand tabulation of responses. Data is presented primarily in the form of frequency tables. (The need for protection of the confidentiality of the small number of female doctors was recognized. In cases when a specific doctor might be identified while discussing both sex and type of practice, true sex of the doctor was not revealed and the pronoun "he" was used in all cases). 
CHAPTER IV

PRESTINTATION OF THE DATA

Interview Completion Rate

Fourteen private practice male subjects were randomly selected from a population of 71 male gynecologists in private practice. The sample represented $19.7 \%$ of the population. Of those sampled, ten, or $71.4 \%$ responded to requests for interviews. In addition, three male Kaiser physicians were selected by stratified random sample to ensure representation of group plan physicians. This sample represented $18.8 \%$ of the Kaiser population. Two of the three, or 66.78 , agreed to be interviewed.

Due to the small percentage of female gynecologists (6.6\% nationally and $6.5 \%$ in the local area), an attempt was made to interview all female gynecologists in the Portland metropolitan area. Of the six female physicians considered appropriate for the study, five, or $83.3 \%$ were interviewed. Table 1 shows the number of physicians sampled, and the distribution of completed interviews for each category. 


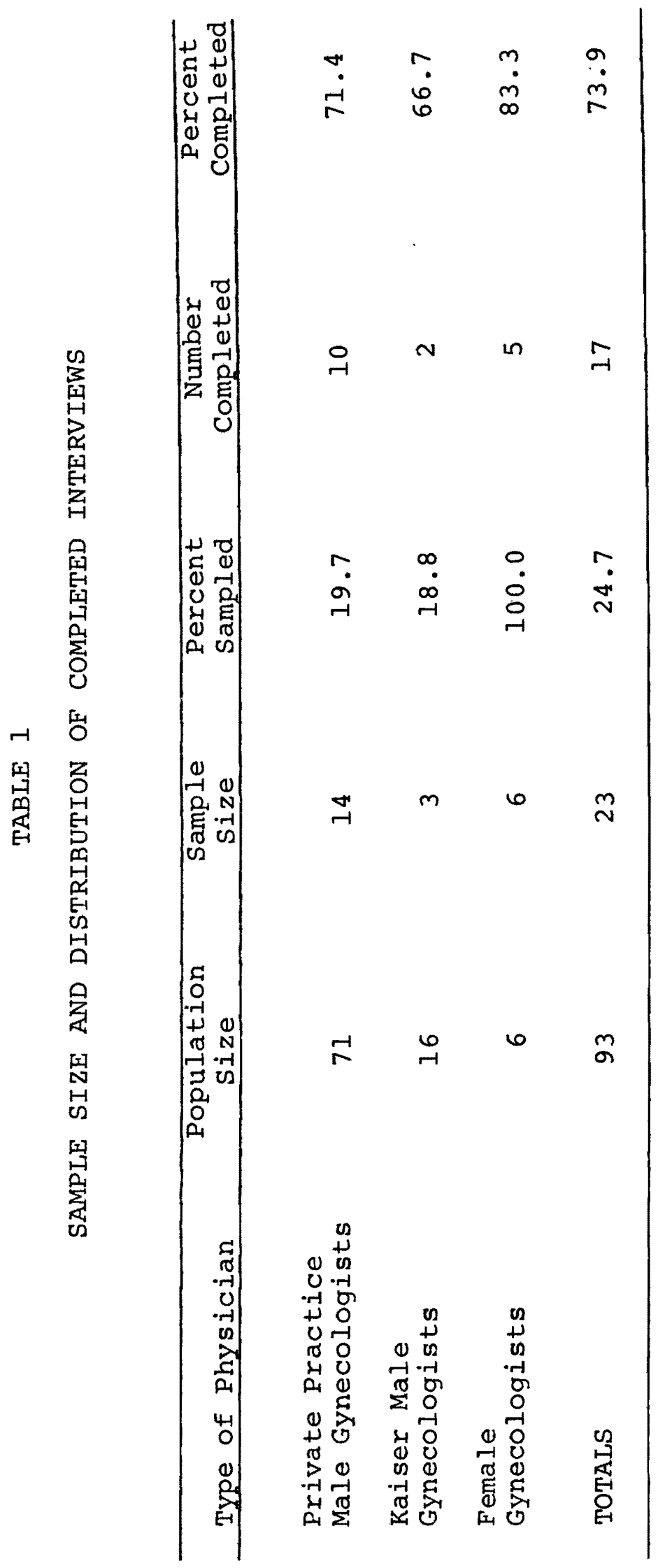


The Physicians and their Practice

Roughly $93 \%$ of the gynecologists in the Portland metropolitan area are male and $7 \%$ female. Physicians from two different types of practice - those employed in their own private practice and those employed at a pre-paid group health plan were studied. Doctors in each type of practice were represented among both the male and female doctors studied. In addition to the two male subjects from the stratified sample of Kaiser male physicians, the two Kaiser female physicians who were included in the population of female gynecologists, were interviewed.

The type of practice of self-employed physicians was further subdivided into three categories of private practice. Distinctions were made between physicians in a solo private practice, physicians in a group practice with other gynecologists, and those physicians in private practice with doctors of other specialties. Table 2 indicates the frequency of doctors, of each sex, in each category of practice. 
TABLE 2

CATEGORIES OF PRIVATE PRACTICE

\begin{tabular}{lccc}
\hline Category of Practice & $\begin{array}{c}\text { Male } \\
\text { Doctors }\end{array}$ & $\begin{array}{c}\text { Female } \\
\text { Doctors }\end{array}$ & $\begin{array}{c}\text { Total } \\
\text { Doctors }\end{array}$ \\
\hline $\begin{array}{l}\text { Private } \\
\text { Solo Practice }\end{array}$ & 4 & 1 & 5 \\
$\begin{array}{l}\text { Private } \\
\text { Group Practice }\end{array}$ & 5 & 1 & 6 \\
$\begin{array}{l}\text { Private } \\
\text { Multi-Specialty Practice }\end{array}$ & 1 & 1 & 2 \\
\hline
\end{tabular}

Physicians were not asked to give their age, but they were asked to state the number of years which they had been practicing. The overall mean of respondents' length of practice was 15 years. The reported range of years in practice for the whole group was from 3 to 33 years. The difference in length of practice between male and female gynecologists was very slight, with the smaller group of females having been in the practice slightly longer. Female doctors reported their years in practice ranging from 4 to 33 with a mean of 17 years; their male counterparts' years in practice ranged from 3 to 31 with a mean of 15 .

When the length of practice of gynecologists in private practice is compared to the length of practice of gynecologists employed by Kaiser (with both males and females included in each group), the results show a marked difference. The number of years in which the self-employed physicians had been in practice ranged from 3 to 33 with a mean of 18 years; 
while the Kaiser physicians had been in practice between 4 and 21 years with a mean of 9 . It appears likely that kaiser gynecologists are a younger group of doctors, since the average number of years they have been practicing is half that of physicians in private practice.

Since physicians for the sample were chosen from those who listed themselves as "Obstetrician/Gynecologists" as well as those who were listed simply as "Gynecologists," doctors were asked how they divided their practice between obstetrics and gynecology. Seventy-one percent of all doctors questioned reported devoting between one-quarter and three-quarters of their total practice to gynecological patients. Not one of the doctors reported devoting less than one-fourth of his time to gynecology. Three of the physicians stated that they limited their practice solely to gynecology. Although the most common type of other-than-gynecological patients seen by these doctors are obstetric patients, one doctor mentioned that he devoted a portion of his practice to patients with endocrine-infertility concerns. Table 3 indicates the proportion of their practice male and female doctors devote to gynecological patients. 
TABLE 3

PERCENTAGE OF PRACTICE DOCTORS DEVOTE

TO GYNECOLOGICAL PATIENTS

\begin{tabular}{lccc}
\hline Percent of Practice * & $\begin{array}{c}\text { Male } \\
\text { Doctors }\end{array}$ & $\begin{array}{c}\text { Female } \\
\text { Doctors }\end{array}$ & $\begin{array}{c}\text { Total } \\
\text { Doctors }\end{array}$ \\
\hline 258 or less & 0 & 0 & 0 \\
$26-508$ & 4 & 2 & 6 \\
$51-758$ & 4 & 2 & 6 \\
more than 758 & 4 & 1 & 5 \\
& 12 & 5 & 17
\end{tabular}

*In instances where doctors reported a range (e.g. 20 $30 \%)$, the midpoint was used.

In an attempt to roughly determine what proportion of doctors' patients might be considered mid-life or possible menopausal patients, doctors were asked what percentage of their gynecological patients were between the ages of 40 and 60. The results are presented in Table 4. Twelve doctors, or $71 \%$, stated that patients between those ages accounted for somewhere between 26 and $50 \%$ of their gynecological practice. Only one doctor devoted more than half his gynecological practice to this age group, four less than one-quarter. 
TABLE 4

PERCENTAGE OF GYNECOLOGICAL PATIENTS

BETWEEN 40 AND 60 YEARS OF AGE

\begin{tabular}{lcccc}
\hline $\begin{array}{l}\text { Percentage } \\
\text { Between } 40 \text { and }\end{array}$ 60 & $\begin{array}{c}\text { Male } \\
\text { Doctors }\end{array}$ & $\begin{array}{c}\text { Female } \\
\text { Doctors }\end{array}$ & $\begin{array}{c}\text { Total } \\
\text { Doctors }\end{array}$ \\
\hline & 2 & 2 & 4 \\
$25 \%$ or less & 9 & 3 & 12 \\
$51-50 \%$ & 1 & 0 & 1 \\
more than $75 \%$ & 0 & 0 & 0 \\
& 12 & 5 & 17 \\
\hline
\end{tabular}

Descriptions of Menopause

When doctors were asked the question - "in general terms, how would you describe menopause?" - their first response was often a dictionary-type of definition. Fourteen of the 17 physicians began their response with a simple statement referring to the cessation of menstruation or the cessation of ovarian function. When probed as to what effect this had for the woman experiencing it, doctors tended to be hesitant in responding. Responses were often prefaced with a statement about the difficulty, or even propriety, of generalizing about patients.

The range of responses tended to be quite broad, and it would be exaggerating only slightly to claim that they were as varied as the physicians themselves. In order to preserve the nature of the responses, it was necessary to categorize them only loosely. These categories, along with 
the descriptive phrases which are indicative of each, are presented below:

TWO DOCTORS made very specific and deliberate attempts at separating the description of menopause from a description of the climacteric. Menopause, it was explained, strictly means the "stopping of menstruation." The climacteric, on the other hand, was described by each of those doctors as a "complex of symptoms" such as...

"vascular abnormalties, ...hot flashes, ...tension, ...irritability, ...anxiety, ...insomnia" "...the autonomic nervous system controlling the blood vessels becomes erratic causing temperature changes - hot and cold flashes."

IN ADDITION, two other doctors spoke primarily of menopause in terms of symtoms experienced such as...

"vasco-motor instability"

"...hot flashes, ...emotional instability..."

ANOTHER DOCTOR distinguished between complaints related to estrogen, "hot flashes, racing heart, palpitations, irritability..."; and "secondary" complaints related to adrenal levels. He explained that the adrenal glands attempt to make up for the low estrogen level but, in addition, they produce an excess of adrenaline. The woman thus suffers from a sometimes "disabling" imbalance, complicated by the adrenal glands, as well as the estrogen level. FOUR OTHER doctors spoke of menopause primarily in terms of hormone changes... 
"...a series of hormonal events, ...ending of reproductive capacity."

"hormone functions change"

"[she] stops having periods and may or may not have other signs of estrogen deprivation."

"going into a resting type of ovarian activity."

While one doctor spoke of it as a "resting type of ovarian activity," others referred to it as ovarian failure. ONE DOCTOR noted that menopause was a new concept. He said that women are living longer. They are living past their ovarian function. He claimed that in contrast, "all other animals produce estrogen until death."

ONE DOCTOR described menopause as a physiological state which, he stated, was not emotionally induced. He likened it to what happens "to men if they're castrated."

ANOTHER DOCTOR explained menopause in terms of "premenstrual tension". He explained that pre-menstrual tension started in adolescence. Over the years, it gradually increases until it reaches a peak at menopause and symptoms, like hot flashes, become more severe."

FINALLY, ONE doctor described it very simply by saying it was the "stopping of periods." In regard to what effect this had for the woman, the doctor stated: "it depends... many are relieved...they're no longer responsible for birth control... [and] some some have problems, side effects due to hormone dimunition..."

Overall, doctors tended to refer to the hormone changes 
involved with menopause and the resulting symptoms this produced. There did not seem to be agreement on the percentage of women who actually experience symptoms. There was also a varying degree among physicians' allusions to emotional symptoms of menopause and the issue of whether or not emotional changes are hormonally related. The female physicians, when describing menopause, tended to limit their descriptions to the physiological aspects of menopause. The male physicians were the ones who mentioned either emotional or social aspects involved.

\section{Doctors' Descriptions Associated with Menopause}

Overall, doctors tended to list specific symptoms when describing the predominant problems that are experienced by women going through menopause. Table 5 presents the frequency with which the most common problems of menopause were mentioned by physicians. (Doctors were allowed multiple responses, thus the total of all responses is higher than 17). 


\section{TABLE 5}

FREQUENCY WITH WHICH DOCTORS MENTION COMMON PROBLEMS EXPERIENCED BY WOMEN GOING THROUGH MENOPAUSE

\begin{tabular}{lccc}
\hline Problems & $\begin{array}{c}\text { Male } \\
\text { Doctors }\end{array}$ & $\begin{array}{c}\text { Female } \\
\text { Doctors }\end{array}$ & $\begin{array}{c}\text { Total } \\
\text { Doctors }\end{array}$ \\
\hline $\begin{array}{l}\text { hot flashes } \\
\begin{array}{l}\text { irritability, anxiety, } \\
\text { nervousness }\end{array}\end{array}$ & 4 & 4 & 8 \\
$\begin{array}{l}\text { bleeding problems or } \\
\text { irregular menses }\end{array}$ & 0 & 0 & 6 \\
$\begin{array}{l}\text { depression } \\
\text { crying or overreacting }\end{array}$ & 3 & 4 & 4 \\
$\begin{array}{l}\text { fear of losing control } \\
\text { lack of sleep }\end{array}$ & 2 & 1 & 3 \\
$\begin{array}{l}\text { "at least half of the } \\
\text { women don't have problems" }\end{array}$ & 1 & 0 & 3 \\
\hline
\end{tabular}

The most common problem mentioned by doctors was "hot flashes" which was referred to by 8 doctors, or 478 of all respondents. The next largest category of problems mentioned was "irritability, anxiety, and nervousness" mentioned by 6 respondents, or 358 of all doctors responding.

It is interesting to note that, with the exception of one, all female responses which referred to symptoms were limited to physiological symptoms. Responses related to emotional symptoms (e.g. irritability, anxiety, nervousness; depression, overreacting, fear of losing control) were made predominantly by male doctors. Of the symptoms that were 
listed by female doctors with the exception of one female gynecologists' mention of depression, symptoms were limited to two categories: hot flashes and bleeding problems or irregular menses. It is also interesting to note that not one male doctor mentioned bleeding problems or irregular menses, both early indications of the onset of menopause. Although the majority of doctors questioned listed physical or emotional symptoms as predominant problems experienced by women in menopause, not all of the doctors questioned viewed menopause in relation to problems. One female doctor stated that if she were seeing a woman for the first time (i.e. that woman had not been a previous patient) she usually came in with concerns over hot flashes. But, in regard to regular patients whom the doctor saw routinely, the predominant concern was usually over irregular - or missed - menses. Some, she stated, were concerned that their condition might even mean a possible pregnancy. This doctor seemed to be implying that many of her regular patients were not even aware they were entering menopause.

In addition, three other doctors commented that at least $50 \%$ of the women they see during menopause do not have any problems. All three of these doctors were employed by Kaiser. One of them stated that women of this age were seen by their clinic on a routine basis. During regular checkups women might mention that they were experiencing hot flashes or having irregular menses; but the doctor felt these were often mentioned simply as comments, rather than as concerns 
over symptoms the women were experiencing as problematic.

Treatment

Doctors were asked about the most common treatment they used for the phenomenon they described as menopause, as well as their reasons for its use. Their responses can be grouped into four distinct types of treatment: 1) hormone replacement therapy, 2) talking to the patient (i.e. providing education and/or reassurance about menopause), 3) using either hormone replacement and/or education or reassurance of the patient depending upon the individual patient problem, and 4) giving the patient information including the pro's and con's of estrogen use, and letting the patient make a decision on treatment. Table 6 indicates the distribution of doctors' use of primary treatments. 
TABLE 6

FORMS OF TREATMENT MOST COMMONLY USED BY DOCTORS

Treatment

Frequency

Percentage

Hormone Replacement Therapy

9

53

Talking to patient:

education and/or reassurance

4

24

Either hormone replacement and/or talking to patient depending upon individual patient

Patient decides given

doctor's information

*Percentage greater than 100 due to rounding.

The most predominant form of treatment mentioned was simple hormone replacement therapy with 53\% of all doctors mentioning this as their most common form of treatment. Hormone replacement therapy involves the use of estrogen to replace the estrogen the body is presumably no longer able to produce. In response to the question of why this form of treatment is used, doctors in this category mentioned that it "alleviates the symptoms" and that it "corrects the deficiency of the lost hormone." Male and female doctors were equally represented in giving these rationales for use.

Doctors in the second category described their treatment 
as talking to their patients. They stressed the importance of providing education about menopause, and reassurance about the naturalness of the phenomenon. In response to reasons for using this form of treatment, doctors appeared split as to physiological and emotional reasons. One of the two female doctors in this group mentioned that it was "less risky" than hormone therapy, and the other doctor stated that since menopause was a natural occurrence, "no treatment was needed." The two males spoke to more emotional needs in women patients. One stated that he uses this form of treatment to ease emotional stress, and the other male doctor said he uses it to dispel fears and misinformation.

The third category was composed of those doctors who used either hormone replacement therapy or talked to the patient depending upon the individual patient's problem. These doctors did not have a sole form of primary treatment, but discriminated between either of the other two forms of primary treatment (or used some combination of both) depending upon the condition of the individual patient. Two of the doctors in this category mentioned that not all women have symptoms or a deficiency of hormones. They said that they use hormone replacement therapy only in those cases where there is an actual hormone deficiency and subsequent need. The third doctor in this category mentioned that he must weigh the risks of cancer in prescribjng hormones. Up to a few years ago, he noted, women had demanded estrogen to alleviate symptoms. Now, he feels, doctors must find other 
forms of treatment besides hormone replacement. He said that doctors can no longer hand over estrogen pills "willy nilly." With the possibility of a relationship between estrogen and cancer, he now has other concerns.

The final treatment category was made up of one doctor, a male, who stated that his primary form of treatment was to explain the pro's and con's of estrogen treatment to women and let them make up their own minds about what they wanted to do. He mentioned that up until January of 1976 he had used estrogen as a primary treatment, but since then he had become aware of studies citing a possible relationship between estrogen and cancer. He now believes he needs to make women aware both of what is going on in their bodies and of the potential risks versus the potential benefits in the use of estrogen. "I give them the information and they have the right to make a choice," he said. "It's their body."

Table 7 presents the distribtion, by respondent's sex, of the forms of treatment most commonly used by doctors. Although, as previously noted, the reasons for using a specific form of treatment have varied among men and women, there generally appears to be only slight difference in the types of treatment they tend to use. 
TABLE 7

DISTRIBUTION, BY SEX, OF THE MOST

COMMON FORMS OF TREATMENT

\begin{tabular}{lcc}
\hline Treatment & $\begin{array}{c}\text { Male } \\
\text { Doctors }\end{array}$ & $\begin{array}{c}\text { Female } \\
\text { Doctors }\end{array}$ \\
& & 7 \\
Hormone Replacement Therapy & $(58 \%)$ & $(40 \%)$ \\
$\begin{array}{l}\text { Talking to patient: } \\
\text { education and/or reassurance }\end{array}$ & $(17 \%)$ & 2 \\
$\begin{array}{l}\text { Either hormone replacement } \\
\text { and/or talking to patient } \\
\text { depending upon individual } \\
\text { patient }\end{array}$ & 2 & $(40 \%)$ \\
$\begin{array}{l}\text { Patient decides given } \\
\text { doctor's information }\end{array}$ & $(17 \%)$ & $(20 \%)$ \\
& 1 & 0 \\
\end{tabular}

There does appear to be a somewhat higher percentage use of education and/or reassurance of the nature of menopause by female doctors and a slightly lower use of hormone replacement therapy as the primary treatment form. Table 8 presents the distribution, by type of doctor's practice, of the use of primary treatment forms. 
TABLE 8

DISTRIBUTION, BY TYPE OF PRACTICE, OF THE MOST COMMON FORMS OF TREATMENT

\begin{tabular}{lcc}
\hline Treatment & $\begin{array}{c}\text { Private Practice } \\
\text { Doctors }\end{array}$ & $\begin{array}{c}\text { Kaiser } \\
\text { Doctors }\end{array}$ \\
\cline { 2 - 3 } & $(69 \%)$ & 0 \\
Hormone Replacement Therapy & 2 & 2 \\
$\begin{array}{l}\text { Talking to patient: } \\
\text { education and/or reassurance }\end{array}$ & $(15 \%)$ & $(50 \%)$ \\
$\begin{array}{l}\text { Either hormone replacement } \\
\text { and/or talking to patient } \\
\text { depending upon individual } \\
\text { patient }\end{array}$ & 1 & \\
$\begin{array}{l}\text { Patient decides given } \\
\text { doctor's information }\end{array}$ & $(8 \%)$ & $(50 \%)$ \\
& 1 & 0 \\
& $(8 \%)$ & 4 \\
\end{tabular}

The results presented in table 8 indicate that, although simple hormone replacement therapy is the overall most frequently used form of primary treatment, as a sole and primary treatment form it is mentioned exclusively by respondents in private practice. No Kaiser physician used simple hormone replacement therapy as a sole and primary form of treatment. Half of the Kaiser doctors (or two) used talking to the patient, or education and reassurance, as the primary treatment form; and the other two Kaiser doctors discriminated between estrogen and talking to the women depending upon the individual woman's needs and condition.

In addition to the most common form of treatment used 
for menopause, doctors were asked what other forms of treatment they used. Table 9 indicates the other forms of treatments used by doctors and the frequency with which they are used as a secondary treatment form. (Percentages are based on the total of 17 doctors. Again, multiple responses were allowed, so the total responses is higher than 17 and the total percentage is greater than 100).

TABLE 9

SECONDARY FORMS OF TREATMENT USED BY DOCTORS

Secondary Treatment Form Frequency

Percentage

Tranquilizers or Sedatives

10

59

Estrogen Replacement

4

24

Counseling or support

4

24

Suggest life-style change

2

12

other drugs (elavil, bellergal)

2

12

Estrogen creme locally

2

12

Vitamin B complex

1

6

Education and/or Reassurance

1

6

Referral to Psychiatrist

1

6

No other (i.e. doctor uses only

primary treatment form)

4

24

The results presented in table 9 indicate that the most frequently mentioned secondary form of treatment are tranquilizers and sedatives. Although the physicians questioned did not stress the use of tranquilizers as a treatment for 
menopause, a total of 10 doctors, or $58.8 \%$ of those questioned, in some way referred to the use of sedatives or tranquilizers for at least some of their menopausal patients.

But, of perhaps even more significance is the finding that when the four doctors who mention use of estrogen as a secondary form of treatment are added to the thirteen doctors who use some form of estrogen therapy as primary treatment, the total number of doctors who at some time, in some form, use estrogen therapy with patients is brought to 17 , or 100 \% of doctors questioned.

Other medical treatments included the prescription of various drugs such as elavil (an anti-depressant), bellergal. (a vasco-constrictor), estrogen creme applied locally for dryness of the vagina, and vitamin B complex.

In addition, four doctors (all male) mentioned the use of counseling or support. Although this concept may seem similar to the education and reassurance used as a primary form of treatment, there is a difference. The doctors who talked of education and reassurance seemed concerned mostly with talking to patients about the occurrence of menopause itself. The doctors using counseling and support seem to be referring more to the emotionally therapeutic aspects of talking to the patients. This is implied by the use of the term "counseling", or - as one doctor put it - "We listen." Two doctors suggested change in life-styles to help with problems associated with menopause. And one doctor mentioned that he sometimes referred patients to a 
psychiatrist. (Psychiatrist referrals were dealt with more completely under another set of questions. See Use of Community Resources.) Four doctors were able to mention no other forms of treatment in addition to those they had already mentioned as a primary treatment.

To summarize, the most predominant form of treatment is hormone replacement therapy. Nine doctors use that form of treatment predominantly for patients and three more use it discriminately depending upon individual patient conditions. one more doctor uses it in response to an educated request from his patient. In total, 13 doctors, or $76.5 \%$ of those questioned in some way use estrogen as a predominant form of treatment. The second most common form of primary treatment involves the use of doctors' education and reassurance of the patient about the occurrence of menopause. Differences in treatment use vary only slightly according to sex of the doctor, but greatly according to type of practice. No Kaiser doctor used estrogen as primary (most common) form of treatment.

Tranquilizers are the most frequently mentioned secondary form of treatment for problems associated with menopause. In addition, the four doctors who mentioned estrogen replacement as a secondary treatment in combination with the 13 doctors who mention some degree of estrogen prescription as a primary treatment brings the number of doctors who at some time prescribe hormone replacement therapy for their patients to 17 , or $100 \%$ of those questioned. 
Awareness and Use of Community Resources

Doctors were asked a series of questions relating to their awareness and use of community resources. First they were asked to state what services, in addition to medical services, were available in this community for women going through menopause - and whether or not they referred women to any of these services.

Two doctors stated that they did not know of any services and did not feel a need to refer patients. One doctor responded by stating that "hormones were the most important aspect in helping family harmony," and that other community services were not needed. (In response to another question, the same doctor stated that physical activities in groups with other women going through menopause would be helpful.) The other doctor expressed an interest in learning of available services but an ignorance of any currently operating due to being "not socially inclined."

A total of 15 doctors responded with descriptions of community based services. Table 10 indicates the type of services and the frequency with which they were mentioned. 
TABLE 10

NON-MEDICAI SERVICES RECOGNIZED BY DOCTORS

Service

Frequency

Mental health related services

Social, physical, or craft activities

Volunteer programs

Awareness groups

Three of the four Kaiser doctors exclusively mentioned services provided by their own health plan. They indicated that they relied heavily upon their own social services department or mental health clinic to handle the other-thanmedical problems experienced by their patients. The other Kaiser doctor also made referrals to these "in-house" services, but in addition was aware of services that existed outside of their health plan.

The methods of referrals of patients to services tended to be handled rather informally by all doctors claiming to use community services. The most widely used method involved simply making a suggestion to the patient that she follow-up by a contact with the service herself. Table 11 indicates the procedures doctors use when making referrals. 
TABLE 11

DOCTORS' PROCEDURES IN MAKING REFERRALS

Procedure

Frequency

Doctor suggests patient contact service 6

Doctor calls service 2

Doctor gives patient name and phone number 2

Doctor makes appointment, requesting feedback 1

Procedure varied or answer unclear $\underline{4}$

Doctors were later shown a list of resources which, they were told, were available in the community. They were questioned about their referral use of each resource, and whether or not they felt the outcome of the referral was satisfactory. Table 12 indicates the frequency with which doctors mentioned each resource. (Percentages are based on the total of 17 doctors. Multiple responses were allowed, so the total responses is higher than 17). 
TABLE 12

DOCTORS' USE OF COMMUNITY RESOURCES

\begin{tabular}{lc}
\hline Community Resource & $\begin{array}{c}\text { Frequency } \\
(\mathrm{N}=17)\end{array}$ \\
\hline Mental Health Clinic & 11 \\
Priest, Minister, or Rabbi & 11 \\
Private Practice Psychiatrist & 9 \\
Private Practice Psychologist & 8 \\
Hospital or Clinic Social Services Dept. & 8 \\
Family Counseling Agency & 7 \\
Employment or Volunteer Service & 6 \\
Adult Education & 5 \\
Women's Health Clinic & 3 \\
Private Practice Social Worker & 2 \\
Community Service Center & 1 \\
Single Women's Groups & 1 \\
Financial Aid Service & 1 \\
Other: Awareness Groups & 1 \\
Sexual Counseling & 1 \\
\hline
\end{tabular}

The two community resources receiving most frequent mention were mental health clinics and members of the clergy. Eleven doctors, or $65 \%$ of all doctors questioned, said they use these community resources for referrals. The mental health clinics mentioned include public and private clinics (usually mentioned by physicians in private practice) and 
the Kaiser clinics. Members of the clergy - including priests, ministers, and rabbis were mentioned by physicians from both private practice and from Kaiser.

The next most frequently mentioned group was private psychiatrists with nine doctors (or $53 \%$ of all doctors) mentioning them as a referral source, followed by private practice psychologists and social service departments, each mentioned by eight doctors (or 47\%). Next came family counseling agencies ( 7 doctors or $41 \%$ ), employment or volunteer services ( 6 doctors or 35\%), and adult education (5 doctors or 29\%). Services that were mentioned as referral sources by less than $20 \%$ of the doctors questioned included: women's health clinics, private practice social workers, community service centers, single women's groups, and financial aid services. Only one doctor referred to a service in response to the "other" category listed on the sheet they were given. This doctor felt that awareness or growth groups were the most important resource in the community. Many examples of these groups were mentioned; his favorite was Life spring. He stated that he would never use the traditional mental health professionals.

Responses were analyzed to determine if there was a difference in the use of the community resources by male and female physicians. Figure 1 presents the results. 
FIGURE 1

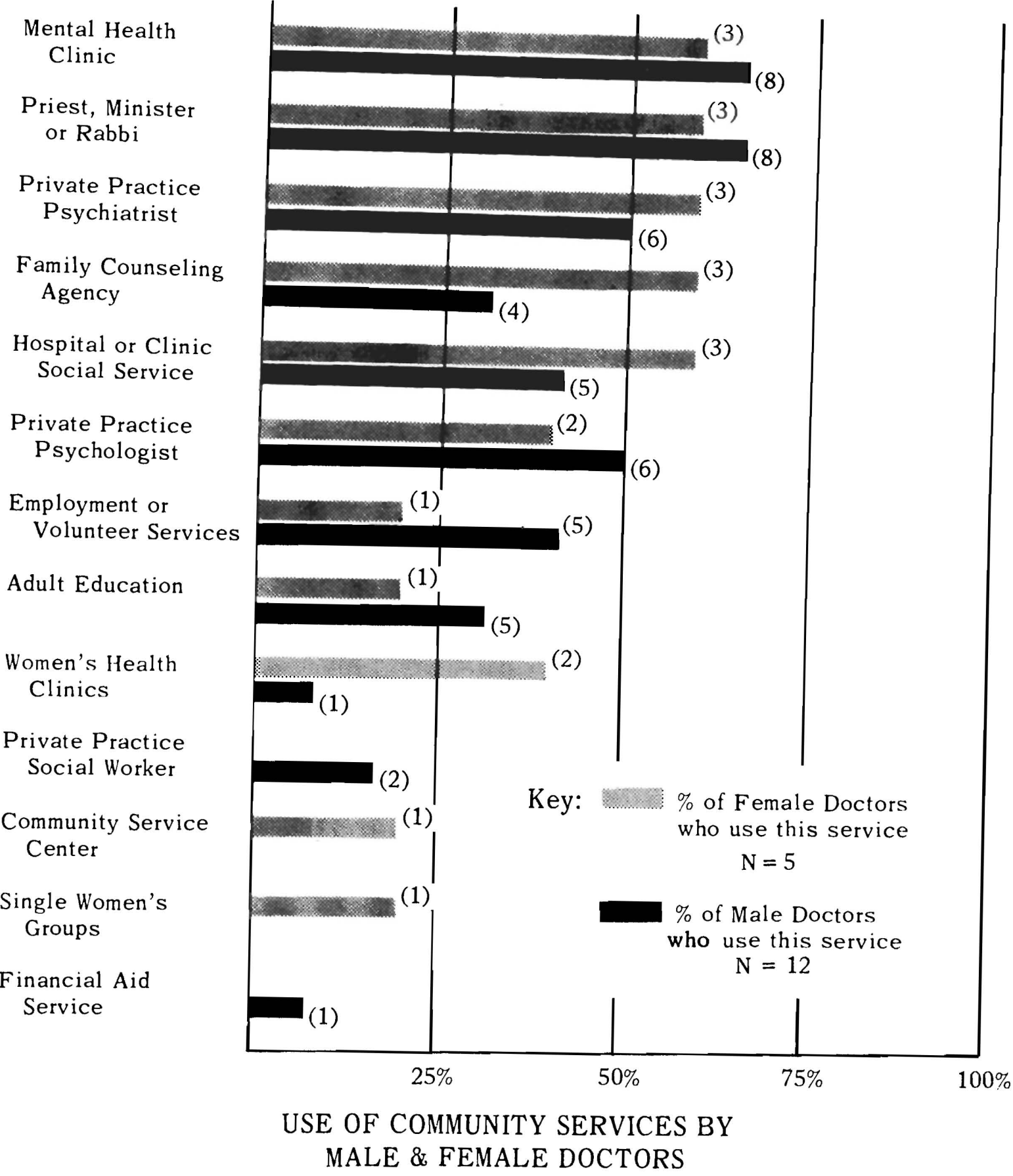

Female physicians $(\mathrm{N}=5)$ were rather consistent in their use of professional services as referral rescurces. The mental health clinics, private practice psychiatrists, family counseling agencies, hospital or clinic social service 
departments, and the clergy were each mentioned as referral sources by 608 of the female physicians questioned.

Male physicians appear to make slightly higher use of mental health clinics and the clergy than their female counterparts, but slightly lower use of private practice psychiatrists and psychologists. In addition, the female physicians mentioned use of family counseling services at a rate of almost double that of their male counterparts, and they mentioned use of hospital or clinic social services at a distinctly higher rate.

It is interesting to note that $40 \%$ of the female doctors mentioned referral to women's health clinics as compared to 88 of the males, and that the only mention of referrals to single women's groups came from female physicians. On the other hand, the rate that male physicians mentioned use of employment or volunteer services was twice that of the female physicians, and the use of private practice social workers and financial aid services was mentioned exclusively by the males.

Responses were also analyzed to determine if there was a difference in the use of community resources by those physicians in private practice, and those employed at Kaiser. Figure 2 presents the rate of referral for each of those groups . 
FIGURE 2

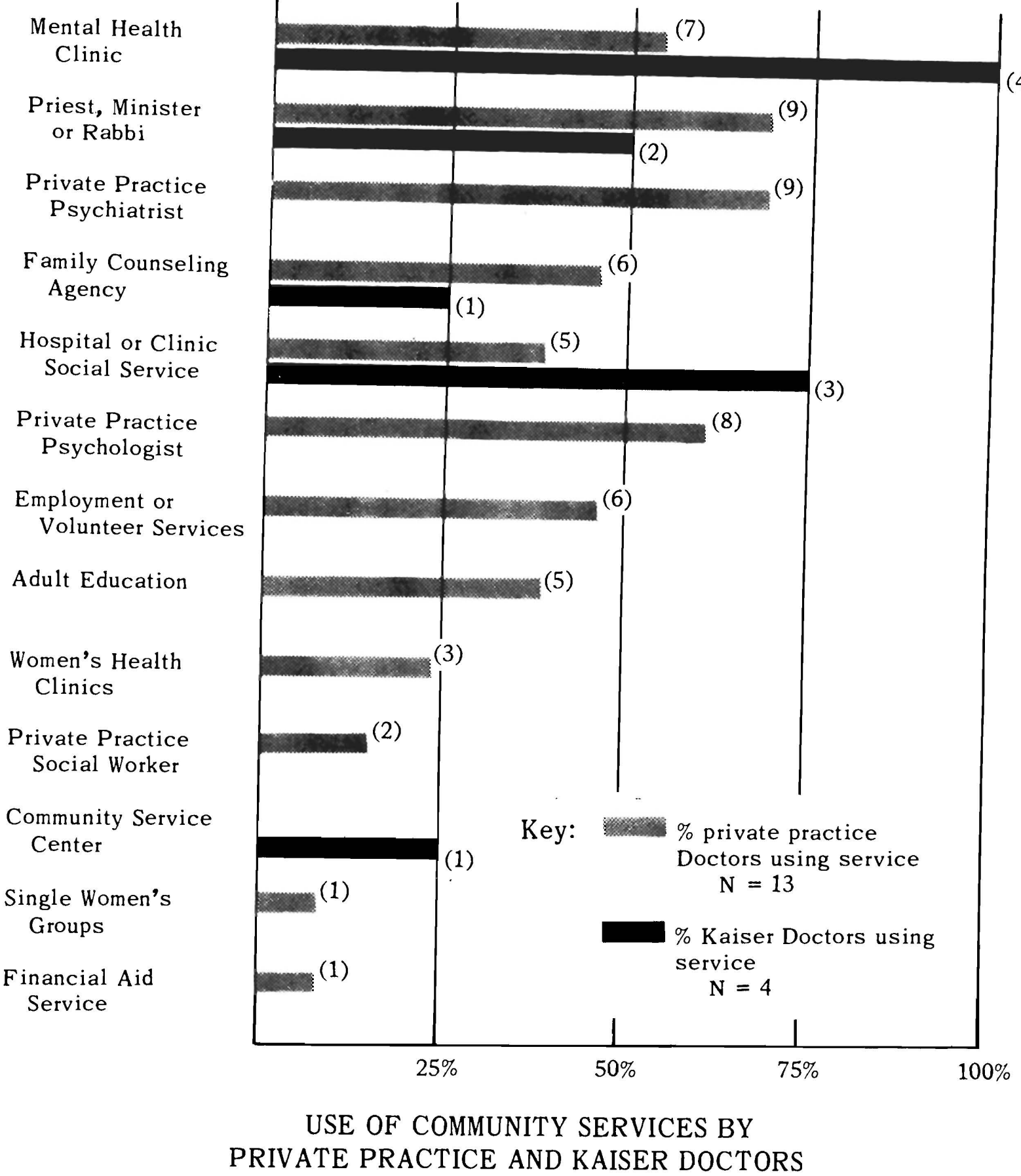

As noted before, the Kaiser clinics in the metropolitan area have their own social service department, as well as their own mental health clinic. The Kaiser physicians tend to primarily use their own services. All Kaiser physicians 
mentioned referrals to their own mental health clinic, and 75\% (three) of them said they referred to their social service department. In addition, half of them said they made referrals to members of the clergy and one doctor mentioned use of family counseling agencies.

Physicians in private practice tended to rely heavily on mental health professionals for referrals. In addition, $46 \%$ mentioned referrals to family counseling agencies, and 698 mentioned referrals to the clergy. Referrals to psychiatrists in private practice were mentioned exclusively by gynecologists in private practice as were referrals to private practice psychologists, employment or volunteer services, adult education, women's health clinics, private practice social workers, single women's groups and financial aid services. The only community resource not receiving mention by any of the physicians in private practice was community service centers, which was mentioned by a Kaiser physician.

Doctor satisfaction with services was not analyzed due to a lack of information on referral outcome available to physicians. It appears that doctors generally do not receive feedback from either the referral source or the patient herself in regard to the outcome of the contact.

In addition to their use of referrals to community services, doctors were questioned about their use of consultation with other professionals regarding the problems experienced by a patient going through menopause. Two doctors 
stated that they did not consult with other professionals, and 15 doctors said that they did. Table 13 indicates the type of professionals with whom they consult. (Doctors were allowed multiple responses, therefore, the total of responses is greater than 15).

TABLE 13

CONSULTATIONS WITH OTHER PROFESSIONALS

Professional Consulted

Psychiatrists

Other medical

Psychologists

Social Workers

Sexual Therapists

clergy 2

Attorney

The majority of professionals consulted were medically trained, either psychiatrists (mentioned by 9 doctors or 538 of all respondents using consultants) or physicians of other medical specialties (mentioned by 6 doctors or 35\%). Five doctors said they consulted with psychologists, four with social workers; two consulted with sexual therapists and two with clergy. There is an interesting contrast between the use of members of the clergy for referrals (used by 11 doctors) and their use as consultants (used by 2 doctors). One 
doctor mentioned the use of an attorney as consultant.

The majority of physicians mentioned using a rather informal source of personal contact for consultations. Six doctors stated consultations were done over the phone. Physicians employed at Kaiser explained that the clinic system made consultation quite simple. Patients see another specialist, but are followed by the same chart; therefore, all physicians have access to the notes of all other physicians. Four doctors stated that a consultation with another physician involved a written or formal report. In an attempt to ascertain if there were any other types of services physicians might find useful for women going through menopause; respondents were asked to describe any services, not now in existence in the community, that they would use if available. Eleven doctors responded "none," and a total of six doctors responded with descriptions of services. Services tended to fall into three categories: groups, information and referral, and comprehensive community service programs. Three doctors talked about groups. Types of groups described included discussion groups, therapy groups, and groups devoted to physj.cal activities. Two doctors said they would appreciate having a central information and referral service available to make them aware of the various community resources, and one doctor stated that a "comprehensive community service program" would be useful. 
Doctors' Perceptions and Attitudes

Doctors were asked a number of questions designed to explore both the perceptions that they have of menopause as a phenomenon, and the attitudes they hold towards the women going through it. In a specific question about menopause, doctors were asked to rank the significance of three aspects - biological, social, and psychological. Table 15 indicates the frequency with which male and female doctors rated either biological or social-psychological aspects as most significant. Social and psychological aspects were later combined since some doctors believed they were tied together and thus thought that they could not really distinguish between them. For example, a doctor might note that the way a woman is feeling (psychological) will affect her family situation (social), and vice versa. In addition, two doctors noted that a woman's view of herself is directly related to - and even the result of - society's view of her. one doctor believed that a lot of these women's problems were due to society's view of aging. "Everyone wants to stay young." "If you're young," another doctor noted "you're good. If you're not, you're no good." And, he suggested, the woman "knows where she is at." 
TABLE 15

MALE AND FEMALE DOCTORS' PERCEPTIONS OF THE MOST SIGNIFICANT ASPECT OF MENOPAUSE

Most Significant Aspect

Male Doctors

Female Doctors

Biological

Social-Psychological

$\begin{array}{cc}7 & 4 \\ (588) & (808)\end{array}$

\begin{tabular}{cc}
5 & 1 \\
$(428)$ & $(208)$ \\
\hline
\end{tabular}

12

(1008)

Although the majority of all doctors viewed the biological aspect of menopause as most significant, the percentage of female doctors holding that view is especially high. The biological aspects of menopause were considered most significant by $80 \%$ of the female doctors as compared to $58 \%$ of the males, while social-psychological aspects were considered most significant by 428 of the male doctors and only $20 \%$ of the females. This appears consistent with the results of questions regarding the description of menopause as well as the one dealing with the problems experienced by the women going through it. In these cases also, female doctors stressed primarily biological characteristics.

In addition, data was analyzed in an attempt to look at the relationship between length of practice and the doctors' perceptions of the most significant aspect of menopause. 
TABLE 16

LENGTH OF DOCTORS' PRACTICE AND THEIR

PERCEPTIONS OF THE MOST SIGNIFICANT

ASPECT OF MENOPAUSE

\begin{tabular}{lcc}
\hline $\begin{array}{c}\text { Most } \\
\text { Significant Aspect }\end{array}$ & $\begin{array}{c}\text { Doctors practicing } \\
\text { less than } \\
\text { l6 years }\end{array}$ & $\begin{array}{c}\text { roctors practicing } \\
16 \text { years } \\
\text { or more }\end{array}$ \\
\hline Biological & 4 & 7 \\
Social-Psychological & $(50 \%)$ & $(78 \%)$ \\
& $\frac{(50 \%)}{8}$ & $\frac{2}{(22 \%)}$ \\
& $(100 \%)$ & $(100 \%)$ \\
\hline
\end{tabular}

While doctors who have been in practice a shorter length of time (less than 16 years) are evenly divided in regards to their views on the most significant aspect of menopause, (biological or social-psychological), more than three-quarters of the doctors who have been in practice 16 years or more view the most significant aspect as biological. These results indicate the possibility that length of practice, in addition to doctor's sex, may be an important factor influencing the doctor's view of menopause.

The reasons doctors gave for holding their respective views were quite varied. One doctor noted listing biological as secondary because menopause was a condition, and not a disease. The other doctors who listed social-psychological aspects as most significant tended to talk about the effects menopause had on the patient. One doctor thought that this 
aspect of menopause was the one that was most distressing to the woman and her family. Another doctor in this category said this was what his patients tended to talk about. Three doctors (or half of those in this category) spoke about the effects of the time of menopause on a woman's self-image. Specific references inclucled: feelings of not being "good for anything" when childbearing years were over; and fears over "loss of attractiveness." There was also mention of the impact of "Madison Avenue" (stressing youth) in reinforcing problems of aging.

In contrast, all but one of the doctors who listed biological aspects as most significant tended to stress the perspective of the physician rather than the effects on the patient. The one doctor in this category who spoke in terms of the patient's perspective said that the binlogical aspects of menopause were most important because the women who have symptoms must live with this daily. The answers of the remaining doctors were equally represented among two types of responses. Half of these doctors $(N=5)$ listed the biological aspects of menopause as most significant since that was the way they defined menopause (i.e. physically or biologically). They spoke of menopause as a condition, one that could be "measured" or treated. The other half of the doctors, in some way, made reference to the causal relationship of the various aspects. The biological aspect was viewed as the primary cause of many of the social or psychological problems. For example, a working woman might be 
having feelings of embarrassment over hot flashes during a board meeting. Although her problems have social and psychological effects for her, their primary cause, according to one doctor, is actually biological.

Another question which attempted to explore doctors' perceptions of menopause asked whether men go through anything similar to menopause. The results are presented in Table 17 .

TABLE 17

DO MEN GO THROUGH ANYTHING SIMILAR TO MENOPAUSE?

\begin{tabular}{|c|c|c|}
\hline Response & Frequency & Percentage \\
\hline Yes & 6 & 35 \\
\hline No & 8 & 47 \\
\hline Maybe & 3 & 18 \\
\hline & 17 & 100 \\
\hline
\end{tabular}

Six doctors believed that men did go through something similar to menopause; eight believed they didn't. Three doctors were not sure, but thought that men "might go through scmething similar. Those doctors who thought that men did go through something similar to menopause spoke of the changes men go through at that time of life (mid-years). Although two of these doctors did refer to actual physiological changes in men at this time, most doctors tended to speak of other types of changes these men experienced. They 
spoke of things such as men's depression over the realization that they had not reached their goals; their feelings about their "declining importance to their families"; and a tendency of looking for younger women in a "clinging to times past."

The majority of male doctors ( 7 or $58 \%$ ) stated that men did not go through anything similar to menopause. Only four male doctors (or one-third) thought that men did go through a "male menopause," and one more male doctor (or $8 \%$ ) believed they might.

In contrast, only one femaje doctor stated that she did not think men went through anything similar to menopause. The remaining $80 \%$ of the female doctors were equally divided between those who responded definitely that men did go through something similar to menopause, and those who were not as definite but thought that they might.

When the issue of a "male menopause" is looked at in relation to the length of time a doctor has been practicing, it appears that the majority of doctors who have been in practice for a longer time (16 years or more), believe that there is not a male menopause. Six of these older doctors (678) responded "no," men do not go through anything similar to menopause; while two doctors in this group (22\%) stated "yes" they did, and one doctor (118) believed it was a possibility.

In contrast, half of the doctors who had been in practice less than 16 years (or four doctors) agreed that men 
did go through something similar to menopause. Another two doctors (or 25\%) thought it was possible. Only the remaining 258 of this group definitely thought they did not.

In addition to asking questions about the phenomenon of menopause itself, doctors were questioned about their perceptions of the women going through menopause. In one question, respondents were asked whether the needs of the women in this age group differed from the needs of other women. Only two doctors thought that these women's needs were not any different from the needs of other women; 15 doctors (or 888) thought that they were. The responses of these 15 doctors were categorized and the results are presented in Table 18. (Since doctors were allowed multiple, responses, the total of all responses is greater than 15). 
TABLE 18

DOCTORS' DESCRIPTIONS OF THE WAYS IN WHICH THE NEEDS OF MID-YEAR WOMEN DIFFER FROM THE NEEDS OF OTHER WOMEN

1. There are changes in their family structure. "...they feel not needed."

2. "They need social activity." Their social and physical activity level is lower.

3. They need more understanding.

"...they need a lot of support." 4

4. "Their self-esteem needs boosting." 2

5. "Decision making is difficult..." 1

6. They have different physical needs. "Their metabolic rate is lower and they need less food." "...they have heavier bleeding... erratic cycles."

7. "They need help with hot flashes." 1

The most frequently mentioned response involved reference to changes in the roles of these women. Seven doctors mentioned differences characterized by change in their family structure. This included references to their children needing less from their mothers or their leaving home altogether, as well as references to changes in the relationship these women had with their husbands. In addition, five doctors mentioned changes which occured in these women's broad social and physical activity spheres.

All female doctors felt that the needs of women in this 
age group were different from the needs of other women. In addition to the responses listed in Table 18 , one female physician - although believing that the needs of these women did, indeed, differ from the needs of other women - stated that she was not prepared to generalize about these differences. Of the remaining four female doctors, their responses were limited to the first two categories: changes in family structure and changes in their activity level. All four of these female physicians commented on changes in the family structure and three of the four mentioned the decrease in activity level.

In addition to the female doctors, three male physicians commented on charges in family structure, and two males referred to the lowered activity level. All other categories were mentioned exclusively by males.

It is interesting to note that female doctors restricted their responses to the first two categories which tend to involve "role changes" for the woman. Categories 3, 4, and 5 tend to involve more psychological or emotional needs and were mentioned only by men. Categories 6 and 7 involve biological needs and were also mentioned by men only.

As a concluding question to the interview, all physicians were asked: "If a member of your immediate family were having problems associated with menopause, what would you advise them to do: [and] where would you advise them to go?" There was a surprising amount of consensus among doctors in response to this question. The majority of 
respondents, or eleven gynecologists, stated that they would advise them to go see a doctor or a gynecologist. Three other gynecologists mentioned medically treating the relative themselves. Another doctor spoke of treating the relative through talking to them, giving nutritional advice, and providing suggestions about activities. One doctor said that he would talk to them about their feelings, and "love them"; and suggest that they see whomever they could talk to best. The final doctor would refer them to a gynecologist or counselor depending upon their particular problem. Overall, it appears that these gynecologists believe that the best form of treatment for their relative would usually involve talking to a medically trained professional either themselves - or another doctor. 
CHAPTER V

\section{DISCUSSION AND CONCLUSIONS}

\section{A Hypothetical Case}

Although we interviewed gynecologists, this study was intended as a vehicle for the exploration of women's experiences and needs at the time of menopause. The study has led us to conclude that a woman's experiences around this time may be different depending upon the sex, the age and the type of practice of the doctor. We will discuss the findings of this research in the form of a hypothetical case study. Below is what might happen to a hypothetical "Ms. Change-ofLife" (Ms. C.O.I.) if she were to visit a gynecologist interviewed in this sample.

Ms. C.O.L. is, shall we say, 48 years old. If she is a mother, her children may be growing up and leaving home. Her parents may be having physical problems associated with advancing age. She has been experiencing some irregularity in her menstrual cycle. In addition, she has been experiencing sudden feelings like blushing in her face during the day and periods of sweating at night which disturb her sleep. She has been concerned about these happenings, and has decided to check with a gynecologist.

Ms. C.O.L. describes these symptoms to the gynecologist. 
Noting her age, the doctor suggest that since the average age of menopause is 50 years, she may be experiencing "premenopausal" symptoms.

If the gynecologist is a woman, she will explain the phenomenon to Ms. C.O.L. in purely biological terms. The female doctor will likely diagnose the feelings of blushing as hot flashes and will note the irregularity of her menstrual cycle. She will probably reassure Ms. C.O.I. that this is a symptom of the onset of menopause, a totally natural phenomenon.

Since the overwhelming number of gynecologists are male, it is more likely that our hypothetical patient will see a male doctor. There is an even chance that the male doctor will explain the menopause to her in purely biological terms, and an even chance that in addition he will bring in social or psychological aspects. He may ask her about her family life, her relationship with her husband, and about the way she has been feeling lately. Has she been feeling irritable, anxious or nervous?

If Ms. C.O.L. belongs to a pre-paid medical program, such as Kaiser, she will probably be seeing a gynecologist for a six month or yearly check-up. It is also likely that her doctor will be fairly young. As she talks with her doctor, she may find comfort in the likely statement of her doctor that, "Half of my patients or more don't have any problems with menopause."

The Kaiser doctor will probably talk to her about 
symptoms she may be experiencing, giving her information and reassurance regarding the nature of menopause. Treatment will be prescribed depending upon the Kaiser doctor's perception of MS. C.O.L.'s individual needs. There is a small possibility that Estrogen Replacement Therapy will be prescribed. There is a much higher probability that ERT will be prescribed if Ms. C.O.L. sees a gynecologist in private practice.

It would be of interest to Ms. C.O.L. to know that one of the three important recent studies that indicate a causal relationship between cancer and the use of estrogen was conducted within the Kaiser system by Kaiser researchers. She might then speculate that this study may have been discussed within the staff meetings and in-service training sessions. She may even wonder if a policy had been developed discouraging Kaiser doctors from the use of ERT for the treatment of menopause.

If Ms. C.O.I. has a history of cancer in herself or family, it is very unlikely that ERT will be prescribed for her regardless of the type of her doctor's practice. Tranquilizers may be prescribed for Ms. C.O.L. as a secondary treatment in either practice setting.

If Ms. C.O.L.'s gynecologist refers her to a nonmedical service, the referral will likely depend upon the doctor's type of practice. A Kaiser doctor will likely refer her within the Kaiser system to either a social services department or to a mental health clinic. In addition, the 
doctor may suggest that she speak with her priest, minister, or rabbi.

Ms. C.O.L. is as likely to be referred to a member of the clergy if she sees a gynecologist in private practice, as if she sees a Kaiser doctor. However, her private practice doctor is more likely to refer her to a local mental health clinic or private psychiatrist or psychologist.

Before leaving her gynecologist's office, Ms. C.O.I. and her doctor might discuss the unique needs of women at this age. Her doctor's discussion will possibly include the changing family role of women at this age which produces feelings of uselessness. The need for more physical and social activity may be mentioned.

Contemplating the uniqueness of this "time of life," Ms. C.O.L. might ask her doctor, "Do men go through anything like this?" The answer to her question will vary depending upon the gynecologist's sex and age. If the doctor is female or in practice a short time, the answer will likely be "yes." An older or male doctor will probably answer negatively.

"By the way doctor," interjects Ms. C.O.L., "what would you tell a member of your family who is experiencing problems related to menopause?" Most doctors would say, "I'd suggest that she follow your example and see a gynecologist!"

\section{Implications for Practice}

Researchers such as Bart and Neugarten stress the negative attitudes our society places on women at the age of menopause. Several of the doctors in our sample suggested 
this as well. One doctor stated that "one of the greatest crimes of western civilization is the idea that woman's usefulness comes to a conclusion with the failure of her ovaries."

Bart (1970) refers to these women as "casualties of our culture." Neugarten (1967) believes that attitudes toward the menopause and the use of medical services for the treatment of menopausal symptoms will depend upon changes in the vast network of attitudes that surround the process of aging, sexuality, and the increasing freedom of middle-aged women."

When doctors in our sample were asked whether the needs of women at this age differed from those of other women, the great majority responded that they did. They mentioned references to role loss, reduced activity, feelings of not being needed, and low self-esteem.

Although these doctors expressed awareness of social needs, the treatments that they use are primarily hormonal therapy together with education and reassurance about menopause, plus tranquilizers. When the doctors used referrals, it was usually to mental health resources.

There is definitely a place for the medical treatment approach, but it does not meet the social needs of middleaged women, which were mentioned by the doctors themselves. We believe it does not begin to attack a basic problem: the need for attitudinal changes in society. Menopause is looked on as negative by women because of the negative way our culture looks on this biological phenomenon and on the aging 
process, particularly in women.

Social workers can play an important role in helping to bring about these changes in societal attitudes. With this in mind, we suggest two possible approaches: education to increase awareness of medical professionals and social work professionals, and the establishment of new resources at this age.

Educational approach. The need for education and awareness about menopause is particularly important since doctors perform a role as transmitters of our culture. Doctors receive very little training and information about menopause in medical school or in the obstetric/gynecology residency (See Chapter II, Gynecologists). This may be why the doctors we interviewed varied so widely in their descriptions of menopause. Moreover, doctors found it difficult to discuss general problems surrounding menopause. Many doctors stated that "each patient is different." Although the individual approach is commendable, it places barriers to receiving general information needed to help menopausal women.

Schools of medicine and social work could establish joint seminars about menopause with both medical and social work students. This could be a beginning step toward providing a broader awareness about menopause and about the needs of middle-aged women.

Medical social workers, because of their contact with medical professionals, could be instrumental in establishing in-service training programs for doctors regarding social 
changes women experience about the time of menopause.

As members of the helping professions, social workers, as well as doctors, need to take into consideration the combination of biological, social, and psychological aspects of menopause. We need to consider what might be going on "when the glands, the genes, the mind, and the culture conspire" (Lear 1974).

New Resources for Women. Doctors, when interviewed, discussed the problems of role change for women around the age of menopause and their need to seek changes in "lifestyles." Recent literature by women (The Boston Women's Health Book Collective 1976, Sheehy 1976) also discuss these needs, but recognize the lack of options available to women at this age. Women may need help to make the transition after losing old roles, and new opportunities need to be opened for middle-aged women. Two doctors in our sample suggested the need for information and referral services for women experiencing menopause.

We suggest the establishment of a resource center for women in the middle years. The objectives of such a center could be:

1) To develop and coordinate resources in the community to provide opportunities for middle-aged women.

2) To provide information and counseling for women to aid them in making decisions moving toward their new stage in life.

3) To provide advocacy for middle-aged women to help 
break down barriers which deny women the potentials for new directions.

4) To provide guidance for the establishment of selfhelp support groups of women experiencing menopause. (Groups were mentioned by some sampled doctors and several women writers).

5) To provide a vehicle for the accumulation of data regarding the experiences of women going through menopause to better evaluate the women's future needs.

From the referral pattern of the gynecologists whom we interviewed, one would not expect gynecologists to be a major source of referrals for a center such as the one described here. It could be a task of the center to educate doctors to the value of such a center.

Limitations of the Research

Before listing the indications for further research on menopause and the experiences of women going through it, certain limitations of this study should be noted.

1. For reasons mentioned in the Methodology section of the study, interviews were limited to doctors who were defined as gynecologists or obstetrician/gynecologists. We cannot know how similar or dissimilar the results might have been if physicians from other disciplines had been interviewed.

2. The interviews focused on the physicians themselves, and on their perceptions of, and attitudes towards, women experiencing menopause. We recognize that not all 
women seek out the help or advice of a physician during the time of menopause.

3. Although we believe that differences in the financial resources among women going through menopause may have a very great effect on the women's experiences, we were not able to explore this issue. There was no feasible way of obtaining this information from the doctors, and difficulties in sampling precluded survey of health care systems which devote much of their practice to subsidized health care. We hope that further research will explore the needs and experiences of women from all social-economic classes.

4. In regard to the specific incidences of doctor referrals to other-than-medical resources, doctors were simply questioned about the types of referral sources they used. They were not questioned about the frequency of their referrals either overall - or to each source individually.

Suggestions for Further Research

One intent of this exploratory research was to clarify the concepts associated with menopause while highlighting the needs of the women who are experiencing it. A second intent was to define a set of questions - or develop a set of hypotheses - which would prove useful to further research. Those relationships which we believe most strongly warrant testing are presented below.

1. Is there a relationship between the doctor's definition of menopause and the type of treatment he/she prescribes? 
This study has reported a variety of doctors' definitions of menopause which range from the doctor who views menopause as a very natural occurence to the doctor who describes it as ovarian failure. When testing the relationship between doctors' definitions and their treatments, one question of interest would be whether those doctors who tend to view menopause as a natural occurrence are less likely to prescribe hormone therapy than their counterparts who view it as ovarian failure. In addition, since there is a possibility that sex, age, and type of practice may influence either definition of menopause or its treatment, special attention should be paid to these variables.

2. Is there a relationship between the source of the doctors' information about menopause and his/her prescribed treatment?

The results of the study have indicated the tendency of the interviewed doctors from Kaiser to use reassurance and/or education as the most common form of primary treatment. In contrast, the majority (69\%) of interviewed doctors who were in private practice used some form of hormone replacement therapy as their most common form of primary treatment.

Wondering about the lower use of hormone therapy among Kaiser doctors, we returned to the review of the literature which revealed that one of the major studies which linked endometrial cancer to estrogen was undertaken by Kaiser. This lead us to hypothesize that word of study results had spread among physicians within the Kaiser system - possibly 
through in-house staffings - and that there was possibly some formal or informal "policy" among Kaiser physicians in regard to a more conservative estrogen use.

Further wondering about the higher use of estrogen therapy among private practitioners in contrast to Kaiser gynecologists, we recalled a seemingly insignificant, though curious, set of incidents which had come to our attention during the interview phase of the study. As noted in the Methodology section, some of the doctors who were interviewed had generously given information resources to us after completing the interview. This also happened once during the pre-test phase of the study. The one book mentioned in the Methodology was a text, and was loaned by the doctor who owned it. But all of the booklets that contained information on menopause, as well as the one tape we were given, were printed by drug companies; and, we presume, were given to the doctors by their sales representatives. They were given to us exclusively by doctors in private practice. In light of the results which show that the majority of private practice physicians use hormone replacement therapy as the most common form of primary treatment, this piece of information was now viewed as possibly not so insignificant after all. In addition, we believe it lends further support for testing the relationship between doctors' sources of information about menopause and type of treatment.

3. Is the experience of the woman going through menopause (including her conceptions of menopause and of 
herself) related to the nature of the health care delivery system?

As previously indicated, when doctors were questioned about the types of problems which were experienced by women going through menopause, three of the four Kaiser doctors interviewed mentioned either $50 \%$ - or more - of their patients didn't have problems. These Kaiser doctors were the only doctors who gave this response in contrast to others who usually listed specific symptoms. In addition to simply noting the interesting fact that all these doctors were from Kaiser, and that they (on their own) gave very similar responses, we wondered what effect this would have on the experiences of their women patients.

We suggest that further research focus attention on the way the organization of service delivery systems (especially the contrast between private practice and pre-paid group health plans) affects the experience of the women who use them. Attention should also be paid to the consequences this has on the women's attitudes towards themselves and their conceptions of the phenomenon they are experiencing.

4. Is there a relationship between the social characteristics of the doctor and his/her definition of menopause as well as his/her treatment and use of referral resources? We conclude that the study results indicate further: research in this area. We suggest testing the significance of the following relationships:

a. the relationship between the doctor's sex and 
his/her definition of menopause.

b. the relationship between the doctor's sex and

his/her attitude and perceptions of women experiencing menopause.

c. the relationship between the type of practice of the doctor and his/her treatment of menopause.

d. the relationship between the type of practice of the doctor and his/her use of referrals and consultation. 


\section{BIBLIOGRAPHY}

Bart, Pauline 1970. "Mother Portnoy's Complaints," TransAction, November - December, 69-74.

1974. "Depression in Middle-Aged Women," Growing Older. by Margaret Hellie Huyck. New Jersey: Prentice-Hall, Inc., 72-78.

1975. "Emotional and Social Status of the older Woman," No Longer Young: The Older Woman In America. The University of Michigan--Wayne State University: The Institute of Gerontology, 3-22.

Bisch, Louis E. 1946. Be Glad You're Neurotic. New York: McGraw Hill Co., Inc.

The Boston Women's Health Book Collective 1976. Our Bodies Ourselves: A Book By And For Women. New York: Simon and Schuster.

Canon, Belle 1973. "Menopause: A deficiency Disease," Human Ecology Forum. 4, August, 8-10.

Cantwell, James R., Editor 1976. Profile of Medical Practice. Chicago: American Medical Association.

Comfort, Alex 1976. The Good Age. New York: Crown Publisher, Inc.

Comprehensive Health Planning Association For The Metropolitan Portland Area 1975. Physician Manpower In Oregon Data Book.

Cooper, Wendy 1975. Don't Change: A Biological Revolution For Women. New York: Stein and Day.

1976. "The Influence of the Media on Women's Requirements For Hormonal Replacement Therapy," The Menopause. Edited by R.J. Beard. Baltimore: University Park Press, 163-175.

Cherry, Sheldon H. 1976. The Menopause Myth. New York: Balantine Books. 
Christie-Brown, J.R.W. and M.E. Christie-Brown 1976. "Psychiatric Disorder Associated with the Menopause," The Menopause. Edited by R.J. Beard. Baltimore: Uni $\overline{v e r}-$ sity Park Press, 5l-81.

Cowgill, Donald 1974. "A Theory of Aging in Cross-Cultural Perspectice," Growing Older. by Margaret Hellie Huyck. New Jersey: Prentice-Hall, Inc.

Crawford, Marion P. and Douglas Hooper 1973. "Menopause, Aging, and Family," Social Science and Medicine, Vol. $7,469-482$.

Deutsch, Helene 1945. "The Climacterium," The Psychology of Women, Vol. 2. New York: Bantam, 47 $\overline{7-509}$.

Donovan, John C. 1951. "The Menopausal Syndrome: A Study of Case Histories," American Journal of Obstetrics and Gynecology, Vol. 62, Number 6, December, 1281-1290.

Ehrenreich, Barbara and Deirdre English 1973. Complaints and Disorders: A Sexual Plitics of Sickness. New York: The Feminist Press.

Gray, R.H. 1976. "The Menopause: Epidemiological and Demographic Considerations," The Menopause. Edited by R.J. Beard. Baltimore: University Park Press, 25-41.

Greenblatt, R.B. 1976. "Estrogens and Endometrial Cancer," The Menopause. Edited by R.J. Beard. Baltimore: University Park Press, 247-263.

Hertz, Roy 1976. "The Estrogen-Cancer Hypothesis," Cancer, July supplement, 534-537.

Huyck, Margaret Hellie 1974. Growing Older: Things You Need To know About Aging. New Jersey: Prentice-Hall, Inc.

Klass, Shirley B. and Margaret A. Redfern 1977. "A Social Work Response to the Middle-Aged Housewife," Social Casework, Vol. 58, No. 2, February, 101-111.

Klemesrud, Judy 1973. "Why Women Are Losing Faith In Their Doctors," McCal1s, June, 76-77, 120-121.

Lake, Alice 1965. "Menopause: Is It Necessary?" Good Housekeeping, April, 85, 159-164.

Lanson, Lucienne 1977. From Woman to Woman: A Gynecologist Answers Questions About You and Your Body. New York: Alfred A. Knopf. 
Lear, Martha Weinman 1974. "Is There A Male Menopause? Or What Is Going on When the Glands, the Genes, the Mind and the Culture Conspire?" Growing older. by Margaret Hellie Huyck. New Jersey: Prentice-Hall, Inc.

Lupton, Mary Jane 1976. "From Leeches to Estrogen: The Menopause," Women: A Journal of Liberation, Vol. $4: 4$,

Mack, Thomas M.; Malcolm C. Pike; Brian E. Henderson; Robert I. Pfeffer; Vibeke R. Gerkins; Mary Arthur; and Sandra E. Brown 1976. "Estrogens and Endometrial Cancer in a Retirement Community," The New England Journal of Medicine, Vol. 294, N. $23,1262-1267$.

McKinlay, Sonja M. and John B. McKinlay 1973. "Selected Studies of the Menopause," Journal of Biosocial Science, 5, 533-555.

Moss, zoe 1970. "It Hurts To Be Alive and Obsolete: The Aging Woman," Sisterhood Is Powerful. Edited by Robin Morgan. New York: Random House, 170-175.

Munter, Pam 1976. "The Middle Years," Oregon Woman's Resource Guide. by Marilyn Schmalle-clark and Nancy Bridgeford. Portland, Oregon: Continuing Education Publications, 87-89.

Neugarten, Bernice L. and Ruth Kraines 1965. "Menopausal. Symptoms in Women of Various Ages," Psychosomatic Medicine, 27, 266-273.

1967. "A New Look At Menopause," Psychology Today, Vol. 1, December, 43-45, 67-69.

and Joan W. Moore 1968. "The Changing Age-Status System," Middle Age and Aging. Chicago: University of Chicago Press, 5-21.

1974. "Age Norms," Growing Older. by Margaret Hèllie Huyck. New Jersey: Prentice-Hall, Inc.

Preston, Caroline E. 1975. "An Old Bag: The Stereotype of the Older Woman," No Longer Young. The University of Michigan--Wayne state University: The Institute of Gerontology.

Proudfit, Carol M. 1976. "Estrogens and Menopause," Journal of the American Medical Association, Vol. 236, No. 8, August 23, 939-940.

Ryan, Kenneth 1975. "Cancer Risk and Estrogen Use in the Menopause," The New England Journal of Medicine, Vol. 236 , No. 8, August 23, 939-940. 
Schmidt, Alexander M. 1976. "Estrogens and the Pill," Parade, September 19, 23.

Scully, Diana and Pauline Bart 1973. "A Funny Thing Happened on the way to the orifice: Women in Gynecology Textbooks," American Journal of Sociology, Vol. 78, Number 4, January, 1045-1050.

Sheehy, Gail 1976. Passages: Predictable Crises of Adult Life. New York: E.P. Dutton and Co., Inc.

Smith, Donald C.; Ross Prentice; Donovan J. Thompsor:; and Walter L. Hertmann 1975. "Association of Exogenous Fstrogen and Endometrial Carcinoma," The New England Journal of Medicine, Vol. 293, No. 23, December, 11641166 .

Solomon, Joan 1974. "Menopause: A Rite of Passage," Ms, December, 16-18.

Sontag, Susan 1975. "The Double Standard of Aging," No Longer young. The University of Michigan-wayne state University: The Institute of Gerontology, 31-41.

"Treating Menopausal Women and climacteric Men" 1974. Medical World News, June 28 .

Webster's New Collegiate Dictionary 1975. Massachusetts: G. and C. Mirriam Co.

Weideger, Paula 1976. Menstruation and Menopause. New York: Alfred A. Knopf.

Weiss, Noel S. 1975. "Risks and Benefits of Estrogen Use," The New England Journal of Medicine, Vol. 293, No. 23, December 4, 1200-1201.

Wilson, Robert A. 1966. Eeminine Forever. New York: M. Evans.

Winokur, George 1973. "Depression in the Menopause," American Journal of Psychiatry, Vol. 130, 92-93.

Ziel, Harry K. and William D. Finkle 1975. "Increased Risk of Endometrial Carcinoma Among Users of Conjugated Estrogens," The New England Journal of Medicine, Vol. 293, No. 23, December 4, 1167-1170. 
APPENDIX A

LETTER TO SAMPLED DOCTORS AND ENCLOSURE 


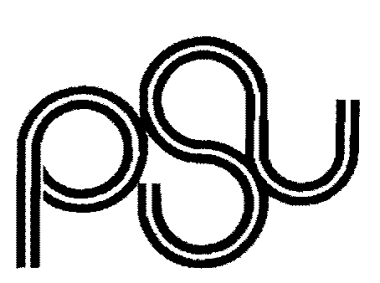

Sept. 30, 1976

As candidates for a degree of Master of Social Work at Portland State University, we are asking for your help in a research study. The study is designed as our thesis project for the completion of our degree.

We are interested in your perceptions, as a practicing gynecolocist, of women going through menopause. We felt that your specialty would uniquely qualify you to be knowledgeable in this area and that your interest in these women would be great.

There is a scarcity of literature in this area that is useful to social workers who are working with women of this ace. We hope that the results of this project, in addition to contributing to the completion of our studies, will help fill this need.

We would like to interview you personally. The interview is designed to last no longer than 20 minutes. We can meet you at your office in the morning before seeing patients, or at the hospital after rounds, or whatever time or place suits your convenience.

Naturally the results of the interview will be held confidential. We will be happy to provide you with a sumary of the results of the study if you desire. We appreciate the volunteering of your valuable, though brief, time for this effort.

We will be calling you in the near future to discuss a specific time for an appointment.

Sincerely, 
Dear Ms. Cogan \& Ms. Konnedy,

Please call me at $\mathrm{AM} / \mathrm{Fin}$ on time day or date to arrange an appointment.

The number is st111 000-0000 or new or alternate number $\therefore$ 


\section{APPENDIX B}

INTERVIEW SCHEDULE 
SCHEDULE FOR INTERVIEW OF GYNECOLOGISTS

1. Doctor's sex

( ) male

( ) female

2. Type of practice
( ) Private - solo
( ) Private - group
( ) Multi-speciality practice
( ) Pre-paid group plan (Kaiser)

3. How many years have you been in practice?

4. How do you divide your practice between $O B$ \& GYN? What percentage of your GYN patients are between 40-60?

5. In general terms, how would you describe menopause? (PROBE)

6. What is the most common treatment you use for the phenomenon you have just described as menopause?

7. Why do you use this treatment? 
8. What other treatments do you use?

9. In your opinion, do men go through anything similar to menopause? (PROBE)

10. We have noticed from our readings that varying professionals have commented on different aspects of menopause, particularly those of a biological, social, or psychological nature. of those three (biological, social, psychological), tell me which you feel is the most significant aspect, which the next, and which the least significant aspect.

Biological

Social.

Psychological

Why? 
11. Of the women who come to you during menopause, what would you say is their predominant problem?

12. What services, in addition to medical services, are available in this community for women going through menopause? (PROBE)

13. Do you ever refer women to any of these services? yes ( ) no () .

14. IF NO: Why not?

IF YES: What procedure do you use for suggestions or referrals? 
15. Here is a list of some resources which are availabie in this community. Please indicate which of these you have heard about or have recommended to a patient, and whether or not the outcome was satisfactory.

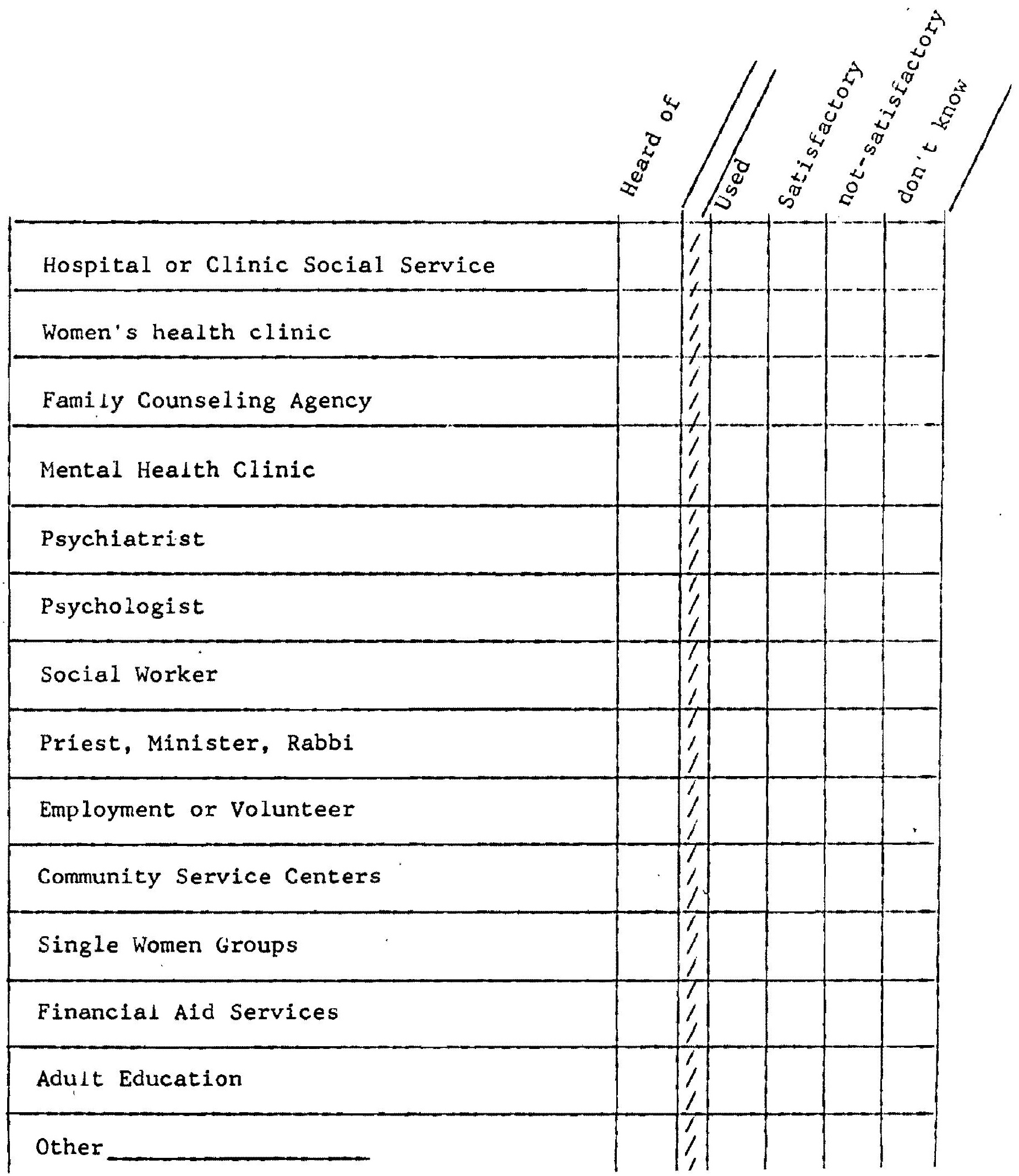


16. Can you describe any services, not now in existance in the community, that you would use if they were available?

17. Do you ever consult with another professional regarding the problems experienced by a patient going through menopause? (Which professionals? What procedures?)

18. Do the needs of the women in this age group differ from the needs of other women?

19. If a member of your immediate family were having problems associated with menopause, what would you advise them to do?

Where would you advise them to go? 
APPENDIX C

LETTER OF ACKNOWLEDGMENT 
Thank you very much for your help with our study of Women in Menopause. Your time and thoughtfulness were most appreciated.

Enclosed is an abstract of our study. We hope that it may stimulate interest and further research in this important area.

\author{
sincerely,
}

zadell Cogan

Sharon Kennedy

$\mathrm{ZC}: \mathrm{SK} / \mathrm{sp}$

Enclosure 